\title{
Market Madness? The Case of Mad Money*
}

\author{
Joseph Engelberg $^{\dagger} \quad$ Caroline Sasseville ${ }^{\ddagger} \quad$ Jared Williams $^{\S}$
}

January 23, 2009

\begin{abstract}
We study the market's reaction to Jim Cramer's recommendations on the television show Mad Money. Average abnormal overnight returns following his recommendations are over $3 \%$ for the entire sample, and $6.7 \%$ for stocks in the smallest quintile. Using a novel dataset of television viewership, we find that the price response is increasing in the number of wealthy viewers who watch the show but unaffected by the number of low income households viewing the recommendations. Consistent with theories of limits to arbitrage, we find that the overnight return is strongest for stocks with high idiosyncratic volatility. Using data from an ECN, we show that the market's response to the recommendations is immediate even though the show airs after the NYSE's trading hours. These price spikes are followed by partial reversals, and short-selling is significantly higher than normal on the day following the recommendations. Equity lending rates are higher in the days following the recommendations, especially for stocks with the largest overnight returns, suggesting that short-selling does not completely eliminate the mispricing in part because it is costly for short-sellers to do so.
\end{abstract}

Keywords: market efficiency, Mad Money, Jim Cramer, stock recommendations, CNBC, investor attention

JEL Classification: G14, G24

\footnotetext{
${ }^{*}$ We thank Flavio de Andrade Jr., Nick Barberis, Fritz Burkhardt, Darwin Choi, Jennifer Conrad, Paul Gao, Dave Haushalter, Zhiguo He, Andrew Hertzberg, Ravi Jagannathan, Pab Jotikasthira, David Matsa, Adam Reed, Ed Van Wesep, and Annette Vissing-Jørgensen for their helpful comments and suggestions. We are especially grateful to Adam Reed for providing us with the equity lending data.

${ }^{\dagger}$ Department of Finance, Kenan-Flagler Business School, University of North Carolina. McColl Building CB 3490, Chapel Hill, NC 27599-3490. E-mail: joseph_engelberg@kenan-flagler.unc.edu.

${ }^{\ddagger}$ Barclays Global Investors, 45 Fremont St \# 1500, San Francisco, CA 94105.

${ }^{\S}$ Department of Finance, Smeal College of Business, Penn State University. 344 Business Building, University Park, PA. E-mail: jmw52@psu.edu
} 


\section{Introduction}

We analyze the market's reaction to first-time buy recommendations of Jim Cramer, host of the CNBC show Mad Money. We find that the average overnight abnormal return following Cramer's recommendations exceeds $3 \%$. This number is economically significant given that the average overnight change in market capitalization following his recommendation is $\$ 56$ million. ${ }^{1}$ There are significant cross-sectional differences in these abnormal overnight returns: the price reaction is strongest for stocks with smaller market capitalization, stocks featured in his "discussion" section of the show and stocks with no other news surrounding the recommendation. Using proprietary data from Nielsen Media Research, we also find that the level of wealthy viewership is strongly related to the market response.

These price spikes occur immediately even though the recommendations are not publicly observed during market hours. Using data from an Electronic Communication Network (ECN), we find unusually high trading volume and returns during the hour of the show's airing. Although the show is usually taped before it airs, ${ }^{2}$ we find no price response during the time of its taping. ${ }^{3}$ The price spikes are followed by partial reversals. Cumulative abnormal returns are significantly negative when the event time is set as the end of the trading day following Cramer's recommendation, especially for stocks with no other news. For example, stocks in which Cramer's recommendation was the only news about the company experience an average abnormal overnight return of $3.8 \%$, but after 50 days, the cumulative abnormal returns for these stocks falls to $1.1 \%$. We also find little evidence that Cramer has skill in selecting stocks, so it is unclear why the market responds at all to his recommendations.

Our findings contribute to several literatures. First, a fundamental issue in asset pricing is how public information is incorporated into prices. As the evidence mounts against the semi-strong form of market efficiency as defined by Fama (1970), several authors have begun to examine whether the response of asset prices to public information is related to how many traders observe that public information. For example, Hong and Stein (1999) build a model in which information diffuses slowly into prices as "newswatchers" slowly acquire information. Huberman and Regev (2001) document the case of cancer drug company EntreMed whose stock price tripled based on a favorable front-page article in the New York Times in May of 1998 even though all the information in the article had been released five months earlier in the journal Nature (and in other press reports). Using a larger sample, Tetlock (2008) also finds differential return patterns based on whether news stories are repeated in the media. DellaVigna and Pollet (2008) find a weaker response to earnings announcements on Fridays when presumably fewer traders are present. A shortcoming in all of these papers is the identification strategy. Although the papers infer that asset prices around information events are

\footnotetext{
${ }^{1}$ This computation is based on abnormal returns, which are defined as the stock's returned minus it's Fama-French matched portfolio. See Section 2 for more details on the matching methodology.

${ }^{2}$ Occasionally the show airs live. For example, as part of his Back to School college tours, Cramer visited the campuses of several universities and taped the 6 p.m. show in front of a live studio audience.

${ }^{3}$ However, Forbes documents one case in which a caller to the show overheard a Cramer recommendation for Syneron Medical and posted the information on a Yahoo message board before the show aired. See http://www.forbes.com/home/management/2005/08/18/cramer-cnbc-madmoney-cz_pl_0819cramer.html.
} 
partially determined by the number of traders who observe the events, none of these papers can directly measure how many traders observe the public information. Authors of earlier studies use proxies for this attention, including trading volume (e.g. Gervais, Kaniel, and Mingelgrin (2001), Barber and Odean (2008), and Hou, Peng, and Xiong (2008)), the existence of news (Barber and Odean (2008)), firms' advertising expenses (Grullon, Kanatas, and Weston (2004)), extreme returns (Barber and Odean (2008)) and up/down markets (Hou, Peng, and Xiong (2008)). While each of these measures may be related to attention, they also capture other effects. For example, the most popular measure of attention - trading volume - is also a popular measure of disagreement in the literature (Chen, Hong, and Stein (2001)). Our paper is different. Because Mad Money is on television, we can measure the TV viewership which witnesses these recommendation events and draw a direct link between the number of traders who observe the event and the consequence for asset prices. As expected, we find a positive relationship between total viewership and overnight return. Moreover, it not only matters how many people are exposed to the recommendations, but the types of people that are exposed to the recommendations. When we divide the total viewership by wealth we find a strong positive relationship between wealthy viewership and overnight return, but no relationship between low income viewership and overnight return. A one standard deviation increase in the number of wealthy households watching the show increases abnormal overnight returns by over 80 basis points. Our results suggest that the link between the exposure of public information and the market response may be more complex than previously thought. In particular, the results suggest that who observes an event may be just as important as how many do.

Second, our setting is ideal for testing whether limits to arbitrage arise when stocks deviate from their fundamental values. Shleifer and Vishny (1997) posit that arbitrageurs are limited in their ability to correct mispricing because prices may diverge even further from fundamental value in the short run, possibly forcing the arbitrageur to liquidate his position at a loss. Assuming the price-reversal pattern we document represents prices temporarily deviating and then returning to fundamental value, we can test Shleifer and Vishny (1997) by examining the relationship between a stock's idiosyncratic volatility and its overnight returns following Cramer's recommendation. Consistent with their theory, we find that stocks with high idiosyncratic volatility exhibit the highest overnight returns following Cramer's recommendations.

Short-sale constraints are another potential limit to arbitrage. If an arbitrageur believes a stock is trading above its fundamental value and he does not already own the stock, he must borrow shares in order to sell the stock. Such borrowing can be costly, especially when there is a lot of demand for borrowing. If short-sale constraints are an insignificant limit to arbitrage, these costs should be unrelated to the level of mispricing. If, however, these costs limit arbitrageurs' ability to correct mispricing, we should expect the short-selling costs to be highest when the stocks deviate furthest from fundamental value. Consistent with the limit to arbitrage prediction, we find that increases in short-selling costs around Cramer's recommendations are significantly related to the overnight returns following the recommendations. That is, the stocks with the highest overnight returns tend to be the stocks that are most expensive to short, controlling for size and other controls. 
Finally, there is a large literature examining stock returns following non-analyst media recommendations. See, for example, Barber and Loeffler (1993) and Liu, Smith, and Syed (1990). Like us, these authors document a price spike and partial reversal following the recommendations. We contribute to this literature by examining whether contemporaneous news announcements mitigate the effects of the recommendation. Controlling for contemporaneous news is important because if the recommendations are based on recent news about the companies, it is unclear whether the market is responding to the recommendations themselves or the news that caused the person to issue the recommendation. We create a news dummy to indicate whether the company had news (other than the recommendation) in the three-day window surrounding the recommendation. We find that the reversals are strongest when there is no news about the company surrounding the recommendation period. That is, when we can isolate the recommendation as the only information event, we find an even stronger pattern of spike/reversal. In our regression analysis, we find that this fact is largely due to the positive correlation between size and the likelihood of news coverage (Chan (2003), Vega (2006), Fang and Peress (2008), Engelberg (2008), Tetlock (2008)). After controlling for size, we find that the effect of other news on the overnight return response is statistically insignificant.

The paper is organized as follows. In Section 2 we describe Mad Money and some basic characteristics of the stocks Cramer tends to recommend. In Section 3 we provide evidence that Cramer's recommendations are followed by significant overnight returns and we run regressions to see which types of recommendations generate the highest overnight returns. We show that the price response is immediate by analyzing after-hours trading in Section 3.1, and we show that the initial spike is followed by reversals in Section 3.2. In Section 3.3 we analyze whether Cramer has skill at selecting stocks, and in Section 3.4 we investigate the short-selling costs following Cramer's recommendations. Section 4 concludes.

\section{Data}

Mad Money is a popular financial television show that airs every weekday evening on CNBC. Its host, Jim Cramer, is a former hedge fund manager who has been described by the popular press as "hyperactive," "hyperkinetic," "bellowing," "blustery" and that "he resembles a cross between a pro wrestler and an air traffic controller." ${ }^{4}$ During each episode, Cramer provides stock recommendations to the sound of bulls roaring, cash registers ringing, bowling pins crashing and a slew of other sound effects.

Our recommendation data consist of the 391 first time buy recommendations made by Jim Cramer on his television show Mad Money between November 16, 2005 and June 23, 2006. ${ }^{5}$ These 391 recommendations are taken from two websites that track Cramer's recommendations: YourMoneyWatch.com and TheStreet.com. YourMoneyWatch.com is unaffiliated with Cramer or CNBC,

\footnotetext{
${ }^{4}$ Sources: Houston Chronicle (July 7, 2005), Boston Herald (February 1, 2006), and Time Magazine (August 15, 2005).

${ }^{5}$ Our sample is restricted to these dates because they are the only dates for which we have both viewership data and short-selling data.
} 
whereas TheStreet.com is affiliated with Cramer, sells Cramer and Mad Money-related products, and posts the prior two months of Cramer's recommendations. There is some disagreement between these two sites, and we restrict attention to the recommendations that appear on both websites. ${ }^{6}$

We are able to match 388 of the 391 recommendations to CRSP and Compustat. We divide his picks into size and book-to-market quintiles based on NYSE cutoff values. The size of each stock is computed at the end of June, and the book-to-market at date $t$ is defined as $\frac{B E}{\text { market }}$, where $B E$ is total assets minus total liabilities and preferred stock plus deferred taxes and convertible debt computed at the end of the latest fiscal year ending before the latest June preceeding date $t$, and "market" is defined as the size of the company in the December preceeding the latest June preceeding date $t .{ }^{7}$ Of the 388 recommendations that can be matched to CRSP and Compustat, 351 are ordinary common shares (excluding Americus Trust Components, closed-end funds, and REITs). Of these 351 stocks, 333 an be matched to a size and book-to-market portfolio. ${ }^{8}$ We present the distribution of his recommendation by quintiles in Table 1 .

\section{[INSERT TABLE 1 HERE]}

We conclude from Table 1 that Cramer has a preference for small growth stocks. There are more picks in the small growth portfolio (39) than in any other, over one third of his recommendations fall in the extreme growth quintile, and nearly a third of his recommendations are in the smallest quintile.

We next examine his distribution of picks by momentum deciles to get a sense of whether he favors momentum strategies or contrarian ones. Every month, we compute the cumulative return over the previous twelve months for every stock in the CRSP database that month with at least 6 previous monthly returns. We then sort the stocks into deciles based on their previous annual return..$^{9}$

Cramer has a tendency of recommending stocks that have done well over the prior twelve months: The distribution of his picks by momentum decile is shown in Table $2 .{ }^{10}$

\footnotetext{
${ }^{6}$ The disagreement probably arises because of the subjective nature of deciding what constitutes a buy recommendation. For example, Cramer sometimes gives conditional recommendations (e.g. "wait three days, then buy") or uses noncommittal language (e.g. "I like the stock"). Of the two major websites that track Cramer's recommendations, YourMoneyWatch.com appears to have the stricter standard of what constitutes a buy recommendation. A description of their criteria can be found at:

http://yourmoneywatch.com/index.php?name=Home\&op=show_buffer\&type=methodology.

We are not concerned by the disagreement between the sites because our results are qualitatively similar when we expand the sample to include all of the stocks that appear on TheStreet.com, the site with the less stringent standards.

${ }^{7}$ Compustat items 6, 181, 10, 35, and 79 are used to compute BE.

${ }^{8}$ The other 18 stocks were not old enough to be assigned to a size and book-to-market portfolio.

${ }^{9}$ More specifically, if Cramer recommends a stock in month $t$, we compute the stock's cumulative return from month $t-12$ through month $t-1$ and rank it relative to the other stocks in the CRSP database.

${ }^{10}$ There are two types of recommendations issued by Cramer-"discussion segment" picks and "lightning round" picks. Since the latter are largely determined by his viewers, the reader might question whether the lightning round recommendations drive this finding. This is not the case-a plurality of his recommendations lie in the winners' decile whether the sample is restricted to lightning round recommendations or discussion segment recommendations.
} 
[INSERT TABLE 2 HERE]

\section{Market Reaction to Cramer's Recommendations}

We begin by analyzing the overnight returns following Cramer's recommendations. We define the overnight return as

$$
\frac{\text { open price }_{t+1}-\text { closing price }_{t}}{\text { closing price }_{t}},
$$

where $t$ is the day of Cramer's recommendation, and $t+1$ is the first trading day following the recommendation. Two of the stocks have missing opening prices on the day following his recommendation, leaving us with a sample of 331 overnight returns.

We define a stock's overnight abnormal return as the difference between its overnight return and the average of all stocks in the CRSP database in the stock's size and book-to-market quintile. Since Mad Money airs at 6:00 PM ET, the recommendations are not made public until after the market closes on the day it is recommended. Hence, the average overnight abnormal return is a measure of the market's reaction to Cramer's recommendation. Table 3 contains the average overnight abnormal return following Cramer's recommendations, by size and book-to-market portfolio. Since small stocks are generally less liquid than large stocks, we expect the average overnight abnormal returns to be highest for stocks in the small portfolio.

\section{[INSERT TABLE 3 HERE]}

The average overnight abnormal return across all 331 stocks is $3.38 \%$. As predicted, the average overnight abnormal returns are highest for the small stocks that Cramer recommends. Among all twenty five portfolios, the abnormal overnight returns are highest for the small growth picks $(8.02 \%)$. These are also the stocks that Cramer is most prone to recommend (see Table 1). The size effect is much stronger than the book-to-market effect: the difference between the average abnormal overnight returns between stocks in the smallest quintile and stocks in the largest quintile is $6.02 \%(6.69 \%-.67 \%)$, while the difference is only $1.11 \%$ between the growth quintile and the value quintile $(3.93 \%-2.82 \%)$.

Another measure of liquidity is developed by Amihud (2002). This measure is defined as

$$
\text { ILLIQUIDITY }=\text { Average }\left(\frac{\left|r_{t}\right|}{\text { Volume }_{t}}\right)
$$

where $r_{t}$ is the stock return on day t and Volume ${ }_{t}$ is the dollar volume on day t. The average is calculated over all positive-volume days from days -34 to -5 (inclusive). We predict that stocks with high ILLIQUIDITY will have high abnormal overnight returns following Cramer's recommendations. 
In Sections 3.2 and 3.4, we show that the overnight spikes in prices following Cramer's recommendations are accompanied by an unusually high volume of short-selling and are followed by partial reversals. This suggests that the initial price spike is temporary mispricing rather than the market rationally updating its valuation in response to news of Cramer's recommendation, and that some market participants are aware of this temporary mispricing. Shleifer and Vishny (1997) argue that stocks with high idiosyncratic volatility are riskier to arbitrage and are therefore less attractive to arbitrageurs. We test this theory by defining the variable IDIOVOL as the standard deviation of the abnormal daily returns from days -34 through -5 , where day 0 represents the day of the recommendation. As before, abnormal returns are defined as the difference between the stock's return and its matched portfolio's return, where the matching is based on size and book-to-market. We predict that stocks with high idiosyncratic volatility will exhibit higher average overnight returns because arbitrageurs are less likely to correct mispricing in high IDIOVOL stocks.

We test our hypotheses by estimating the following model for log abnormal overnight returns (AOR):

$$
\log (1+\mathrm{AOR})=\alpha+\beta_{\text {size }} S I Z E+\beta_{\text {illiquidity }} I L L I Q U I D I T Y+\beta_{\text {idiovol }} I D I O V O L+\varepsilon,
$$

where $L O G$ SIZE is a liquidity measure defined as the natural log of the stock's market cap at the close of the recommendation day, ILLIQUIDITY is the illiquidity measure as defined by Amihud (2002), and IDIOVOL is the stock's idiosyncratic volatility. We hypothesize that $\beta_{\text {size }}<0$ and $\beta_{\text {illiquidity }}>0$ due to liquidity and that $\beta_{\text {idiovol }}>0$ because it represents a limit to arbitrage.

The regression results are presented in Column 1 of Table 5. The coefficient of SIZE is significantly negative, and the coefficients of illiquidity and IDIOVOL are significantly positive, as predicted.

The positive coefficient of IDIOVOL is evidence that idiosyncratic volatility hinders arbitrageurs from keeping prices close to fundamental value, as predicted by Shleifer and Vishny (1997). Previous researchers have found evidence supporting Shleifer and Vishny (1997) by investigating the relationship between idiosyncratic volatility (as measured by the CAPM) and various anomalies, including post-earnings announcement drift (Mendenhall (2004)), the book-to-market effect (Ali, Hwang, and Trombley (2003)), and the accrual anomaly (Mashruwala, Rajgopal, and Shevlin (2006)). In particular, they show that the aforementioned anomalies are most pronounced among stocks with high idiosyncratic volatility. To the extent that the CAPM is a valid asset pricing model, these results suggest that idiosyncratic risk is a limit to arbitrage. However, Choi (2009) provides evidence that even the Fama and French (1993) three factor model omits risk factors, and that stocks with high idiosyncratic volatility (relative to the Fama and French (1993) 3 factor model) load on these factors. Hence, the results from previous studies comparing return anomalies and idiosyncratic volatility might be driven by loadings on omitted risk factors. Assuming the spike-reversal pattern 
we document is not driven by loadings on omitted risk factors, our evidence supporting Shleifer and Vishny (1997) is immune from the omitted risk factor critique.

\section{[INSERT TABLE 5 HERE]}

It is not obvious that the overnight returns we observe are entirely driven by Cramer's recommendations. It is conceivable that Cramer bases his recommendation on current news, and that the price spikes we observe are caused by the market reacting to this news rather than to Cramer's recommendation. To test whether this is driving our results, we search Factiva for any news article about the stock on the trading day before Cramer's recommendation, on the day of the recommendation, or on the day after the recommendation. We used a combination of company name, ticker, and Factiva company code to to identify firms in articles. We exclude articles in which the stock was mentioned in a table (e.g. a table of mutual fund holdings or a table of the day's highest volume stocks) and exclude articles in which Cramer's recommendation was the news event in the article. The dummy variable NEWS takes the value 1 if there is a news article during that three day window. Therefore, the NEWS variable identifies the observations that had news unrelated to Cramer's recommendation.

Column 2 of Table 5 presents the regression results of the following model for log abnormal overnight returns:

$\log (1+\mathrm{AOR})=\alpha+\beta_{\text {size }} S I Z E+\beta_{\text {illiquidity }} I L L I Q U I D I T Y+\beta_{\text {idiovol }} I D I O V O L+\beta_{\text {news }} N E W S+\varepsilon$.

We include SIZE, ILLIQUIDITY, and IDIOVOL in all of our regressions because we believe they affect how well the market can accomodate the buying pressure exerted by Mad Money viewers.

The coefficient on NEWS is insignificant, supporting our assertion that the overnight returns we observe are driven by his recommendation rather than simultaneous news events. We will see in Section 3.1 that the returns are concentrated during the hour Mad Money airs, which further supports our view that his recommendations cause the price spikes we observe.

We now begin analyzing factors affecting the amount of buying pressure exerted by Mad Money viewers. A unique feature of our setting relative to the others in the literature is that we can accurately measure how many people are exposed to the recommendations, as well as what types of people are exposed to the recommendations using data from Nielsen Media Research.

Nielsen Media Research is a firm that specializes in audience measurement. They estimate the number of people who view each television show each day, as well as the demographics (e.g., age, wealth, race, education, etc.) of the viewers for each show each day. Since Mad Money airs three times each weekday-first at 6 PM ET with reruns at 9 PM and midnight-we have several options for our measure of the number of viewers exposed to his recommendations. We restrict our 
attention to the $6 \mathrm{PM}$ viewership. ${ }^{11}$ The mean viewership for the 6 PM showings among the 123 episodes in our sample is 213,000, with values ranging from 73,000 to 304,000 ( $\sigma=44,000)$.

Because stock market participation is heavily concentrated among the wealthiest individuals (see, e.g., Table 6 in Vissing-Jørgensen (2003)), we expect the number of high income viewers to be an important factor in explaining the level of overnight abnormal returns following Cramer's recommendations. Defining wealthy viewers as those with household income above $\$ 60,000$, the average number of high income households viewing Mad Money during our sample is 140,940 households with a standard deviation of $33,940 .{ }^{12}$

We estimate the following model of abnormal overnight returns in Column 3 of Table 5:

$$
\begin{aligned}
\log (1+\mathrm{AOR})= & \alpha+\beta_{\text {size }} \text { SIZE }+\beta_{\text {illiquidity }} \text { ILLIQUIDITY }+\beta_{\text {idiovol }} \text { IDIOVOL } \\
& +\beta_{\text {high }} H I G H \text { INC VIEWERSHIP }+\beta_{\text {low }} L O W I N C \text { VIEWERSHIP }+\varepsilon .
\end{aligned}
$$

As predicted, the coefficient $\beta_{\text {high }}$ is positive, while the coefficient $\beta_{\text {low }}$ is insignificant. The positive relationship between wealthy viewership and abnormal overnight returns is economically significant. A one standard deviation increase in HIGH INC VIWERSHIP increases abnormal overnight returns by over 80 basis points when all other variables are set to their means. ${ }^{13}$ In contrast, we find no evidence of a relationship between the number of low income individuals exposed to the recommendations and abnormal overnight returns.

We expect three other factors to affect the magnitude of buying pressure following Cramer's recommendations. First, Cramer's discussion segment picks should generate more buying pressure than his lightning round picks. Cramer uses the discussion segment to recommend stocks that he finds particularly attractive. These recommendations are usually accompanied by detailed descriptions of the company's business and his reasons for believing the stock is a good buy. In contrast, the stocks discussed during the lightning round are chosen by viewers of the show, and Cramer's lightning round buy recommendations are generally accompanied by much less justification than his discussion segment picks.

We also expect the number of recommendations Cramer issues alongside the recommendation to impact buying pressure. For example, if Cramer only recommends one stock during an episode, every viewer choosing to follow Cramer's advice will buy that one stock. However, if he recommends five stocks, some viewers will likely only invest in a subset of the recommendations, whereas others will invest in a different subset of the recommendations. This leads us to hypothesize that overnight abnormal returns are highest for stocks that are recommended on days when there are few competing recommendations.

\footnotetext{
${ }^{11}$ We choose this measure in part because the market prices are already significantly affected by 7 PM. See Section 3.1

${ }^{12}$ We define wealthy households as those earning more than $\$ 60,000$ because the median income for a four person family in the United States is $\$ 62,732$. (Source: http://www.census.gov/hhes/www/income/4person.html)

${ }^{13}$ For this calculation we use the model in Column 5 , which includes all of the variables used in our regressions.
} 
Finally, we include a variable capturing stock's momentum decile based on the prior twelve months' returns. It remains an open question whether investors are more likely to believe in mean reverting or trending stock returns because the existing evidence is mixed. De Bondt (1991) analyzes economic forecasters' responses to the Livingston survey and find strong evidence that their predictions are mean-reverting. However, in a later study De Bondt (1993) analyzed survey responses of non-experts and found evidence consistent with investor belief in continuation of trends in stock prices. Griffin, Harris, and Topaloglu (2003) find that individual investors are more likely to be net purchasers of the worst performing stocks than of the best performing stocks, suggesting that individual investors are more likely to believe in mean reversion of stock returns than are institutional investors.

We estimate the following model:

$$
\begin{aligned}
\log (1+\mathrm{AOR})= & \alpha+\beta_{\text {size }} \text { SIZE }+\beta_{\text {illiquidity }} \text { ILLIQUIDITY }+\beta_{\text {idiovol }} \text { IDIOVOL } \\
& +\beta_{\text {lightround }} \text { LIGHTROUND }+\beta_{\text {num }} \text { NUM PICKS } \\
& +\beta_{\text {decile }} \text { MOMENTUM DECILE }+\varepsilon .
\end{aligned}
$$

The results are shown in Column 4 of Table 5. LIGHTROUND is a dummy for whether the pick was given during the lightning round. NUM PICKS is defined as the number of discussion segment picks (excluding the recommendation under consideration) that were made on the day of the recommendation. MOMENTUM DECILE is calculated by ranking the stocks' previous 12 month returns across all stocks in the CRSP universe. Decile 0 (9) contains the extreme losers (winners).

The coefficient of LIGHTROUND is significantly negative, consistent with our prediction that prices rise more following Cramer's discussion segment picks than for his lightning round picks.

The coefficient on NUM PICKS is also significantly negative, confirming our prediction that the price response tends to be stronger when the recommendation is accompanied by fewer other recommendations. This is similar to a recent finding by Hirshleifer, Lim, and Teoh (2007), who analyze how the market's reaction to companies' earnings announcements is affected by the number of other companies that announce earnings on the same day. They find that the price and volume reaction to earnings announcements are weaker, and that post earnings announcement drift is stronger, when many other companies announce earnings on the same day.

The coefficient on MOMENTUM DECILE is significantly negative, suggesting that viewers are more likely to act on Cramer's contrarian picks than his momentum picks. This result seems related to the finding by Griffin, Harris, and Topaloglu (2003) that individual investors are more likely to be net buyers of poorly performing stocks than of well performing stocks. Moreover, it supports the notion that individual investors believe that stock returns mean revert. 
Column 5 of Table 5 contains the results of the regression including all of the independent variables. The signs of all the variables are the same in the reduced models as in the full model, and the statistical significance of the variables is qualitatively similar for all of the variables. In Columns 6 and 7 we restrict the sample to the set of all discussion segment picks and lightning round picks, respectively. ${ }^{14}$ We see that the model works much better at explaining the abnormal overnight returns for the discussion segment picks than the lightning round picks: statistical significance is greater for all of the coefficients in the discussion segment sample (including the intercept), and the $R^{2}$ is also higher. All of this suggests that viewers are more likely to act on Cramer's discussion segment recommendations than his lightning round ones.

\subsection{Speed of the Market's Response}

We have already seen that Cramer's recommendations are followed by statistically and economically significant overnight returns, particularly among small stocks (see Table 3). These overnight returns are based on the opening price the day following the recommendation and the closing price the day of the recommendation. The recommendations are made between these times. ${ }^{15}$ We now turn our attention to the timing of the market's response to the news. Three scenarios are possible. First, prices might rise and trading volume might be high before Cramer issues his recommendations. Since Cramer's recommendations have a predictable impact on market prices, insiders who are aware of the recommendations (e.g. the film crew) have an incentive to trade on this information. Also, if Cramer recommends stocks based on recent news events, it's possible that the returns are driven by the underlying news event, and not the recommendations themselves. Another possibility is that the market is slow to respond to Cramer's recommendations. If this were true, one could easily profit from the recommendations by buying the stocks in the after hours market as soon as they are made public. The final possibility is that the market reacts to the information as soon as they are made public and that immediate, short-run returns are unpredictable.

To determine which of these scenarios are true, we obtain after-hours transactions from an ECN. Our data are from NASDAQ's historical Totalview-ITCH which records all orders and executions on the NASDAQ system for securities listed on NASDAQ, NYSE, AMEX and regional exchanges. ${ }^{16}$ It also includes orders and executions over INET - the Instinet Group's ECN that NASDAQ acquired in December of 2005. The ECN orders and executions are particularly relevant for our study since Cramer's recommendations are made after hours.

We display the average returns in the after hours of the days of Cramer's recommendations in the top half of Figure 1. The price at each time (in multiples of 30 minutes) is defined as the price of the last trade on the ECN prior to that time. The base price for the return calculations is the price of the last trade on the ECN prior to the 6 PM start of Mad Money. The price response occurs during the hour Mad Money airs-from 6 to 7. Before 6, the price run-up is economically

\footnotetext{
${ }^{14}$ We do not include LIGHTROUND since its value does not vary within these samples.

${ }^{15}$ Mad Money airs from 6 to 7 PM ET.

${ }^{16}$ http://www.nasdaqtrader.com/Trader.aspx?id=ITCH
} 
insignificant and barely statistically significant. ${ }^{17}$

\section{[INSERT FIGURE 1 HERE]}

Recall from Table 5 that there are cross-sectional differences in the overnight returns of Cramer's recommendations. For example, the overnight return is significantly higher for small stocks than large stocks, and for discussion segment recommendations than for lightning round recommendations. If these differences in returns do not arise immediately, one could profitably exploit the differences by buying the stocks with relatively high overnight returns (e.g., small stocks) in the after-hours market and selling the stocks with relatively low overnight returns (e.g., large stocks). In the bottom half of Figure 1, the after hours returns are plotted by size quintile. During the hour the show airs, the returns are much higher for the smallest stocks than the largest ones.

In the top half of Figure 2, we show that the price spike is larger for firms with no news in the 3 day window surrounding the recommendation date than it is for firms with news. Since NEWS is insignificant in the regressions in Table 5 , this result is likely driven by the positive correlation between $N E W S$ and SIZE $(\rho=.275)$. In the bottom half of Figure 2, we divide the stocks by recommendation type-lightning round or discussion segment. Recall that Cramer spends more time justifying his discussion segment and that these recommendations are associated with larger overnight abnormal returns (Table 5).

[INSERT FIGURE 2 HERE]

Our findings suggest the cross-sectional differences in overnight returns arise within the hour the show airs. Moreover, our findings that the price spikes occur during the hour Mad Money airs and that the spikes are larger for the stocks without simultaneous news events imply that Cramer's recommendations, rather than contemporaneous news events, are the primary cause of the price spikes we document.

We arrive at similar conclusions by examining trading volume in the after hours market. Figure 3 displays the recommended stock's turnover on the ECN (scaled by 1000) during each 30 minute interval. There is scant evidence of abnormal trading volume before the show's airing but clear evidence of abnormal trading volume during the show's airing. Trading volume remains unusually high following the show's airing even though prices remain flat. ${ }^{18}$

\section{[INSERT FIGURE 3 HERE]}

\footnotetext{
${ }^{17}$ The upper bound for the confidence interval at $4: 30$ is $-.04 \%$.

${ }^{18}$ Recall that the show airs between 6:00 and 7:00.
} 


\subsection{Longer Horizon Impact of Cramer's Recommendations}

We have shown that Cramer's recommendations are followed by significant abnormal returns, and that these returns occur immediately following the recommendations. We now examine whether the price impact is persistent or transitory.

We plot the cumulative abnormal returns in event time in Figures 4 and 5. Abnormal returns are computed by taking the difference between the stock's daily return and the average daily return of the stock's matched portfolio, where the matching is done based on size and book-to-market quintiles. The event is Cramer's recommendation, and time is measured in trading days, where day 0 corresponds to the day of the recommendation. The $95 \%$ confidence interval is obtained via bootstrap sampling (10,000 replications).

\section{[INSERT FIGURE 4 HERE]}

The price spikes induced by Cramer's recommendations are followed by partial reversals. The cumulative abnormal returns drop below $2 \%$ nineteen days after the recommendation, down from a high of over $3 \%$ two days after the recommendation. ${ }^{19}$ The spike-reversal pattern is most pronounced for the smallest quintile of stocks: the lower bound of the $95 \%$ confidence interval for the average abnormal return after one day-4.9\%-is larger than the upper bound for the cumulative abnormal returns after 30 days $-4.7 \%$. Hence, in our sample the strategy of shorting the smallest stocks recommended by Cramer after he recommends them and buying the shares back thirty days later is profitable with high statistical significance. This profit-more than $4.6 \%$ over thirty trading days-is also economically significant.

We predict the spike-reversal pattern to be stronger among the recommendations with no concurrent news events than for the recommendations with concurrent news events. To test this, we compare the cumulative abnormal returns of the recommendations with news events during the three day window surrounding the recommendation with the recommendations without news events in the three day window surrounding the recommendation. We confirm this prediction in Figure 5. Indeed, among the stocks with news events, the cumulative abnormal return after 50 days is actually higher than the cumulative abnormal returns after 1 day (2.7\% versus $2.0 \%)$, whereas the cumulative abnormal returns drop to $1.1 \%$ from $3.8 \%$ for the recommendations without news events.

\section{[INSERT FIGURE 5 HERE]}

In Figure 6 we plot daily turnover in event time. His effect on trading volume is short-lived compared to his effect on stock prices.

\footnotetext{
${ }^{19}$ In an earlier version of this paper, we documented a complete reversal following the recommendations. The difference is due to a change in our methodology. Before, we used a four factor model to compute the benchmark returns. Since Cramer's recommendations tend to be momentum picks, they generally had high $\alpha$ 's in our pre-event estimation window. We were then essentially subtracting away this (often positive) $\alpha$ in the post-event window, leading to an overestimation of the reversal.
} 


\section{[INSERT FIGURE 6 HERE]}

\subsection{Should the Market React to Cramer's Recommendations?}

We have shown that Cramer's buy recommendations are followed by abnormal positive returns and high levels of trading volume. This begs the question of whether Cramer has skill at identifying mispriced stocks. If he has such skill, the abnormal returns following his recommendations might be consistent with the market rationally incorporating the news of the recommendation into the stocks' prices. Because the price spikes following his recommendations are followed by reversals, we hypothesize that this is not the case. That is, we hypothesize that trading strategies based on Cramer's buy recommendations do not yield positive alphas.

To test this hypothesis we analyze the performance of various portfolios that follow Cramer's advice. In Table 6 we consider portfolios composed of stocks from our entire sample. Because we are only interested in Cramer's effect on prices, we also consider stocks with no other news events surrounding the recommendation in Table 7 . We consider strategies that wait $0 / 1$ trading days before buying and that hold for 50/100/250 trading days. We then compute monthly returns from these calendar-time portfolios and regress these monthly returns on the Fama-French factors and a momentum factor.

\section{[INSERT TABLES 6 AND 7 HERE]}

Strategies that buy one day after Cramer's recommendation have negative alpha. For example, a strategy which buys stocks with no other news one day after the recommendation and holds them for 50 trading days has an alpha of -110 basis points per month. When we consider portfolios that are formed on the day of the recommendation, we find a positive alpha that shrinks over the holding period as the benefit from the initial spike becomes less significant to the trading strategy. ${ }^{20}$ In all of these specifications, even when we include the price spike, we find no statistically detectable positive alpha, although this may be due to the fact that we have a short time series.

\subsection{Short Selling}

Since Cramer's recommendations are followed by a spike-reversal pattern, the strategy of shorting the recommended stock after the recommendation and buying it back later is profitable. Moreover, in Section 3.3 we showed that there is little evidence that Cramer has stock picking ability. Hence, we predict that some traders are aware of Cramer's effect on prices and that they short the recommended stocks following his recommendation.

\footnotetext{
${ }^{20}$ This strategy cannot be implemented by viewers because it is based on future information-the recommendation, which does not occur until after the market closes. Nevertheless, we compute the alpha because it is a measure of Cramer's skill that is not biased against him (since it does not assume the stocks are bought after the initial price spike).
} 
To test this, we compute the volume of short selling using NYSE's Reg SHO database. Of Cramer's 391 recommendations, we were able to match 206 of them to the Reg SHO database. Of these, 175 are ordinary common shares. We restrict attention to these 175 stocks.

We plot the short selling volume in event time in the top half of Figure 7. The vertical axis represents "short turnover," defined as short sale volume divided by shares outstanding (multiplied by 1,000). Time is measured in trading days, and day 0 is the day of the recommendation.

\section{[INSERT FIGURE 7 HERE]}

A clear pattern emerges. As predicted, there is a significant increase in short turnover on the day after Cramer's recommendation. The mean short turnover rises from 2.5 to 4.2 from day 0 to day 1 . The lower bound of the $95 \%$ confidence interval on day $1,3.5$, is higher than the upper bound on day $0,3.0$.

Moreover, because the spike-reversal pattern is most evident in stocks that do not have news releases around the time of Cramer's recommendation (see Figure 5), we predict that the increase in short selling should be most pronounced for stocks without news releases. This is confirmed in the bottom panel of Figure 7, where we divide the sample based on whether the stock had a news release in the 3 days surrounding the recommendation. The amount of short volume in the two samples is similar before the recommendation causes them to diverge.

Earlier in our analysis we showed that stocks with high idiosyncratic volatility have lower abnormal overnight returns following Cramer's recommendations. Our explanation for this finding is that stocks with high idiosyncratic volatility are riskier to arbitrage, and institutional traders are less likely to short these stocks following his recommendations for this reason. Another factor affecting institutions' willingness to short is the cost of shorting as measured by the difference between the federal funds rate and the rebate rate. (The rebate rate is the interest rate paid on the collateral posted by the short seller when borrowing the shares to sell.) We predict that there will be a significant increase in the demand for borrowing the stocks recommended by Cramer with high abnormal overnight returns, and that this demand will increase the costs of shorting the stocks. We also hypothesize that this effect will be less strong for stocks with high idiosyncratic volatility since these stocks are less attractive to arbitrageurs.

To test these hypotheses we obtain equity lending data from a data provider that is both a market maker in the equity loan market and a data provider for major equity lenders. See Kolasinski, Reed, and Ringgenberg (2008) for a more detailed description of the equity lending data. For every stock on every day, the lending database reports the weighted average rebate rate calculated from the loan portfolios of 12 lenders. We define a variable called Specialness as the difference between the federal funds rate and the weighted average rebate rate. As Reed (2007) argues, "This measure of specialness represents scarcity in the equity loan market on a daily basis." To quantify the change in specialness around the recommendation event, we define a variable called SPECIALNESS CHANGE which is the average specialness in the 10 days before the recommendation 
minus the average specialness in the 10 days after the recommendation. This variable is defined (non-missing before and after the recommendation event) for 303 of our 388 recommendations.

In Column Table 8 we present the results of the following regression:

$$
\text { SPECIALNESS CHANGE }=\alpha+\beta_{\text {overnight }} \text { OVERNIGHT RETURN }+\varepsilon .
$$

$\beta_{\text {overnight }}$ is significantly positive, confirming our prediction. In column 2 we test the hypothesis that the increase in borrowing costs is lower for stocks with high idiosyncratic volatility by running the following regression:

$$
\text { SPECIALNESS CHANGE }=\alpha+\beta_{\text {overnight }} \text { OVERNIGHT RETURN }+\beta_{\text {idiovol }} I D I O V O L+\varepsilon .
$$

As expected, the coefficient on IDIOVOL is significantly negative. This evidence supports the notion that stocks with high idiosyncratic volatility are perceived as being riskier for arbitrageurs and is yet another piece of evidence in support of Shleifer and Vishny (1997).

The regression results presented in Column 4 suggest that the effect of OVERNIGHT RETURN on SPECIALNESS CHANGE is nonlinear, with the relationship being most pronounced for stocks that have the highest abnormal overnight returns (RETURN QUINTILE 5).

Finally, Columns 3 and 5 present the coefficient estimates when all of the variables used in Table 5 are included.

\section{Conclusion}

We showed that Jim Cramer influences market prices through his recommendations on the show Mad Money. We found that overnight returns following his recommendations are highest for small stocks, stocks with high idiosyncratic volatility, stocks recommended on days when wealthy viewership is high, stocks that have performed relatively poorly over the previous twelve months, stocks recommended on days when relatively few recommendations are issued, and stocks recommended during the discussion segment (as opposed to the lightning round). Although the show airs after NYSE trading hours, prices respond immediately in the after hours market. We examined the trading profits one would earn by following Cramer's advice, and we found no evidence that such strategies earn positive alpha. Finally, since short selling is significantly higher than usual on the day following Cramer's recommendations, we concluded that some market participants profit from the spike-reversal phenomenon that follows his recommendations. These arbitrageurs do not push 
prices back to fundamental value in part because the cost of short-selling also rises following Cramer's recommendations. 


\section{References}

Ali, A., L.-S. Hwang, and M. Trombley (2003): "Arbitrage Risk and the Book-to-Market Anomaly," Journal of Financial Economics, 69, 355-373.

Aminud, Y. (2002): "Illiquidity and Stock Returns: Cross-section and Time Series Effects," Journal of Financial Markets, 5, 31-56.

Barber, B., And D. Loeffler (1993): "The "Dartboard" Column: Second-Hand Information and Price Pressure," The Journal of Financial and Quantitative Analysis, 28, 273-284.

Barber, B., And T. Odean (2008): "All that Glitters: The Effect of Attention and News on the Buying Behavior of Individual and Institutional Investors," The Review of Financial Studies, 21, 785-818.

Chan, W. (2003): "Stock Price Reaction to News and No News: Drift and Reversal after Headlines," Journal of Financial Economics, 70, 223-260.

Chen, J., H. Hong, and J. Stein (2001): "Forecasting Crashes: Trading Volume, Past Returns, and Conditional Skewness in Stock Prices," Journal of Financial Economics, 61, 345-381.

Chor, D. (2009): "Omitted Markets, Idiosyncratic Risk, and the Cross-Section of Stock Returns," Working Paper.

De Bondt, W. (1991): "What do Economists know about the Stock Market?," Journal of Portfolio Management, pp. 84-91.

(1993): "Betting on Trends: Intuitive Forecasts of Financial Risk and Return," International Journal of Forecasting, 9, 355-371.

DellaVigna, S., and J. Pollet (2008): "Investor Inattention and Friday Earnings Announcements," Journal of Finance (forthcoming).

EngelberG, J. (2008): "Costly Information Processing: Evidence from Earnings Announcements," Working Paper.

FAmA, E. (1970): "Efficient Capital Markets: A Review of Theory and Empirical Work," The Journal of Finance, 25, 383-417.

Fama, E., and K. French (1993): "Common Risk Factors in the Returns on Stocks and Bonds," Journal of Financial Economics, 33, 3-56.

FAng, L., And J. Peress (2008): "Media Coverage and the Cross-Section of Expected Returns," Journal of Financial Economics, Forthcoming.

Gervais, S., R. Kaniel, and D. Mingelgrin (2001): "The High-Volume Return Premium," The Journal of Finance, 56, 877-919. 
Griffin, J., J. Harris, and S. Topaloglu (2003): "The Dynamics of Institutional and Individual Trading," The Journal of Finance, 58, 2285-2320.

Grullon, G., G. Kanatas, and J. Weston (2004): "Advertising, Breadth of Ownership, and Liquidity," The Review of Financial Studies, 17, 439-461.

Hirshleifer, D., S. S. Lim, and S. H. Teoh (2007): "Driven to Distraction: Extraneous Events and Underreaction to Earnings News," Working Paper.

Hong, H., And J. Stein (1999): "A Unified Theory of Underreaction, Momentum Trading, and Overreaction in Asset Markets," The Journal of Finance, 54, 2143-2184.

Hou, K., L. Peng, and W. Xiong (2008): "A Tale of Two Anomalies: The Implications of Investor Attention for Price and Earnings Momentum," Working Paper.

Huberman, G., and T. Regev (2001): "Contagious Speculation and a Cure for Cancer: A Nonevent that Made Stock Prices Soar," The Journal of Finance, 56, 387-396.

Kolasinski, A., A. Reed, And M. Ringgenberg (2008): "A Multiple Lender Approach to Understanding Supply and Demand in the Equity Lending Market," Working Paper.

Liu, P., S. D. Smith, And A. A. Syed (1990): "Stock Price Reactions to The Wall Street Journal's Securities Recommendations," The Journal of Financial and Quantitative Analysis, 25, 399-410.

Mashruwala, C., S. Rajgopal, and T. Shevlin (2006): "Why is the Accrual Anomaly not Arbitraged Away? The Role of Idiosyncratic Risk and Transaction Costs," Journal of Accounting and Economics, 42, 3-33.

Mendenhall, R. (2004): "Arbitrage Risk and Post-Earnings-Announcement Drift," Journal of Business, 77, 875-894.

Reed, A. (2007): "Costly Short Selling and Stock Price Adjustment to Earnings Announcements," Working Paper.

Shleifer, A., And R. Vishny (1997): "The Limits of Arbitrage," The Journal of Finance, 52, $35-55$.

Tetlock, P. (2008): "All the News Thats Fit to Reprint: Do Investors React to Stale Information?," Working Paper.

Vega, C. (2006): "Stock Price Reaction to Public and Private Information," Journal of Financial Economics, 82, 103-133.

Vissing-JøRGensen, A. (2003): "Perspectives on Behavioral Finance: Does "Irrationality" Disappear with Wealth? Evidence from Expectations and Actions," NBER Macroeconomics Annual. 
Table 1: Distribution of Cramer's Recommendations by Size and BM Quintiles

\begin{tabular}{|c|c|c|c|c|c|c|c|}
\hline & & cowtl & & & & val & \\
\hline Size / & & 1 & 2 & 3 & 4 & 5 & sum \\
\hline (small) & 1 & 39 & 24 & 20 & 15 & 11 & 109 \\
\hline & 2 & 23 & 11 & 10 & 10 & 4 & 58 \\
\hline & 3 & 19 & 12 & 6 & 9 & 5 & 51 \\
\hline & 4 & 19 & 10 & 8 & 5 & 2 & 44 \\
\hline (big) & 5 & 28 & 15 & 9 & 7 & 12 & 71 \\
\hline & & 128 & 72 & 53 & 46 & 34 & 333 \\
\hline
\end{tabular}

Table 1: We report the distribution of Cramer's recommendations among the twenty-five size and bookto-market portfolios. The sample size, 333, represents the number of his recommendations that could be matched to one of the twenty-five portfolios.

Table 2: Distribution of Cramer's Recommendations by Momentum Decile

\begin{tabular}{cccc|c} 
Decile & Lightning Round & Discussion Segment & Total \\
\hline (Losers) & 0 & 2 & 9 & 11 \\
& 1 & 6 & 25 & 31 \\
2 & 7 & 18 & 25 \\
3 & 7 & 22 & 29 \\
4 & 7 & 17 & 24 \\
& 5 & 8 & 18 & 26 \\
6 & 16 & 21 & 37 \\
& 7 & 11 & 34 & 45 \\
& 8 & 26 & 49 & 75 \\
(Winners) & 9 & 33 & 52 & 85 \\
\hline & & 123 & 265 & 388
\end{tabular}

Table 2: We report the distribution of Cramer's picks by momentum decile. Cramer makes two types of recommendations during his show: "lightning round" recommendations and and "discussion segment" recommendations. The former occur "on the spot" when viewers call to ask Cramer about the stock and he responds by recommending they buy the stock. The latter are more in-depth recommendations that are planned by Cramer before the show is filmed. 
Table 3: Average Abnormal Overnight Returns Following Cramer's Recommendations by 25 Size and BM Quintiles

\begin{tabular}{|c|c|c|c|c|c|c|c|}
\hline & & growth & & & & (value & \\
\hline Size / & & 1 & 2 & 3 & 4 & 5 & Avg \\
\hline (small) & 1 & $8.02 \%$ & $7.76 \%$ & $3.52 \%$ & $6.33 \%$ & $5.85 \%$ & $6.69 \%$ \\
\hline & 2 & $4.78 \%$ & $3.77 \%$ & $1.92 \%$ & $2.01 \%$ & $2.07 \%$ & $3.43 \%$ \\
\hline & 3 & $1.96 \%$ & $1.69 \%$ & $2.46 \%$ & $1.51 \%$ & $2.07 \%$ & $1.88 \%$ \\
\hline & 4 & $1.20 \%$ & $0.63 \%$ & $1.52 \%$ & $0.49 \%$ & $3.36 \%$ & $1.16 \%$ \\
\hline (big) & 5 & $0.71 \%$ & $0.45 \%$ & $0.63 \%$ & $1.29 \%$ & $0.51 \%$ & $0.67 \%$ \\
\hline & & $3.93 \%$ & $3.62 \%$ & $2.31 \%$ & $3.10 \%$ & $2.82 \%$ & $3.38 \%$ \\
\hline
\end{tabular}

Table 3: We report the average overnight abnormal returns following Cramer's recommendations for each of the twenty-five size and book-to-market portfolios. The $(i, j)$ entry contains the average return for the stocks in the $i$ th size portfolio and the $j$ th book-to-market portfolio. The right most entry in rows 1 through five contain the average returns for the 5 size portfolios. The bottom entry in columns 1 through 5 contain the average return for the 5 book-to-market portfolios. The bottom right entry, $3.38 \%$, is the average overnight abnormal return across all of the 331 stocks for which an abnormal overnight return can be computed.

Table 4: Abnormal Overnight Return by Momentum Decile

\begin{tabular}{cccc} 
& Decile & Abnormal Return & $\mathrm{N}$ \\
\hline (Losers) & 0 & $8.9 \%$ & 9 \\
& 1 & $5.9 \%$ & 28 \\
& 2 & $5.2 \%$ & 23 \\
& 3 & $1.8 \%$ & 24 \\
& 4 & $2.6 \%$ & 21 \\
& 5 & $1.1 \%$ & 21 \\
& 6 & $1.9 \%$ & 30 \\
& 7 & $3.2 \%$ & 39 \\
& 8 & $3.1 \%$ & 66 \\
(Winners) & 9 & $3.5 \%$ & 70 \\
\hline
\end{tabular}

Table 4: We report the average overnight abnormal returns following Cramer's recommendations by momentum decile. The total sample size is 331 because we can only compute cumulative abnormal returns for 331 of his recommendations. 


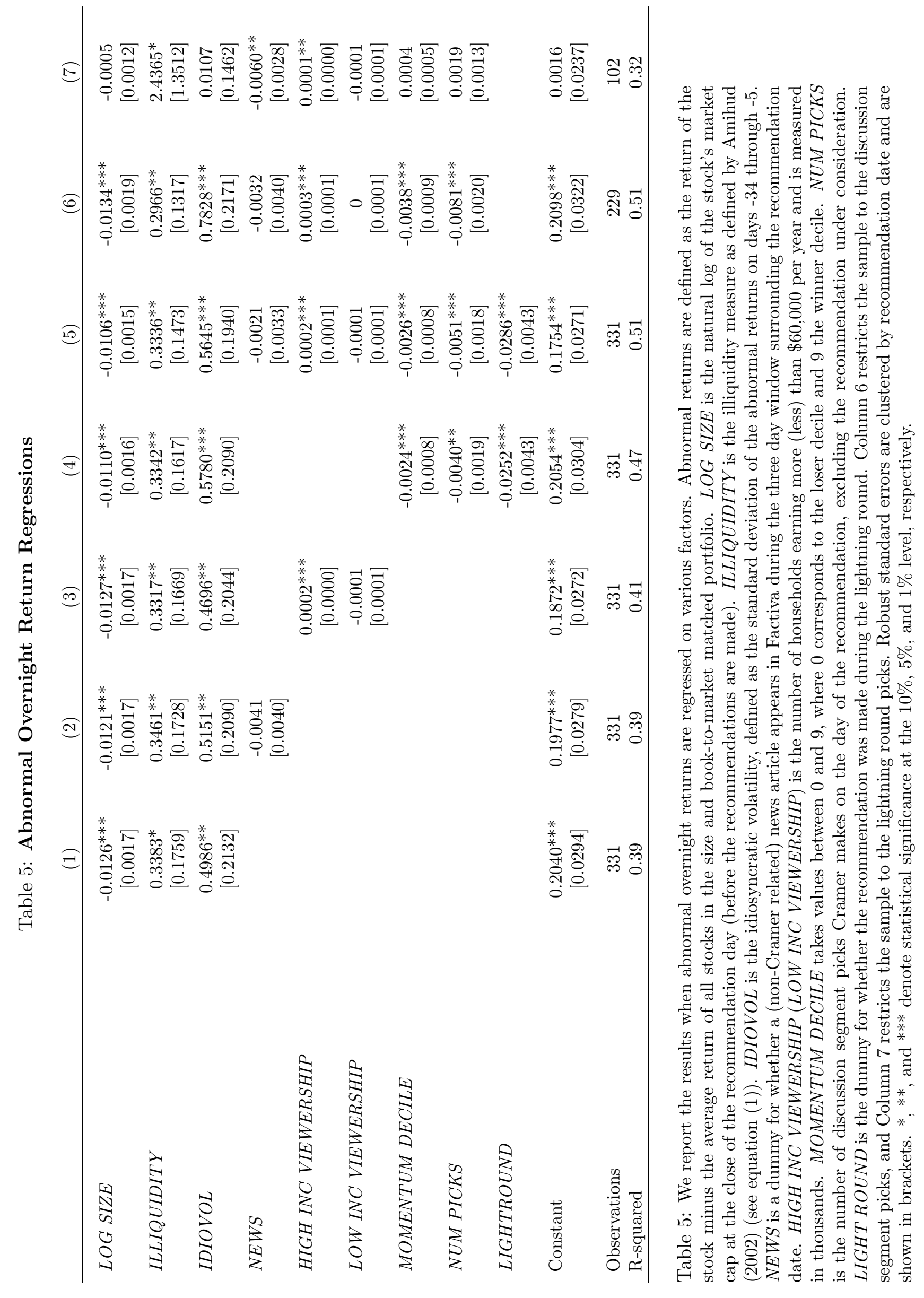


Table 6: Analysis of Cramer's Stock-Picking Ability, Entire Sample

\begin{tabular}{|c|c|c|c|c|c|}
\hline \multicolumn{6}{|c|}{ Panel A: Portfolios Formed 1 Day after Recommendation } \\
\hline \multicolumn{2}{|c|}{ Hold Stocks 50 Days } & \multicolumn{2}{|c|}{ Hold Stocks 100 Days } & \multicolumn{2}{|c|}{ Hold Stocks 250 Days } \\
\hline Intercept & $\begin{array}{l}-0.010 \\
(0.007)\end{array}$ & Intercept & $\begin{array}{l}-0.009 \\
(0.006)\end{array}$ & Intercept & $\begin{array}{l}-0.006 \\
(0.004)\end{array}$ \\
\hline MktMinusRF & $\begin{array}{c}0.611 \\
(0.432)\end{array}$ & MktMinusRF & $\begin{array}{l}1.049^{* *} \\
(0.369)\end{array}$ & MktMinusRF & $\begin{array}{c}1.280^{* * *} \\
(0.185)\end{array}$ \\
\hline SMB & $\begin{array}{c}1.398^{* * *} \\
(0.375)\end{array}$ & SMB & $\begin{array}{c}1.055^{* * *} \\
(0.335)\end{array}$ & $\mathrm{SMB}$ & $\begin{array}{c}0.635^{* * *} \\
(0.129)\end{array}$ \\
\hline HML & $\begin{array}{c}0.347 \\
(0.386)\end{array}$ & HML & $\begin{array}{c}0.487 \\
(0.421)\end{array}$ & HML & $\begin{array}{c}0.250 \\
(0.274)\end{array}$ \\
\hline Mom & $\begin{array}{r}-0.401 \\
(0.461)\end{array}$ & Mom & $\begin{array}{l}-0.350 \\
(0.343)\end{array}$ & Mom & $\begin{array}{c}-0.011 \\
(0.152)\end{array}$ \\
\hline $\begin{array}{l}\text { Observations } \\
\text { R-Square }\end{array}$ & $\begin{array}{c}11 \\
0.8832\end{array}$ & $\begin{array}{l}\text { Observations } \\
\text { R-Square }\end{array}$ & $\begin{array}{c}13 \\
0.8482\end{array}$ & $\begin{array}{l}\text { Observations } \\
\text { R-Square }\end{array}$ & $\begin{array}{c}20 \\
0.8768\end{array}$ \\
\hline \multicolumn{6}{|c|}{ Panel B: Portfolios Formed on Day of Recommendation } \\
\hline \multicolumn{2}{|c|}{ Hold Stocks 50 Days } & \multicolumn{2}{|c|}{ Hold Stocks 100 Days } & \multicolumn{2}{|c|}{ Hold Stocks 250 Days } \\
\hline Intercept & $\begin{array}{c}0.005 \\
(0.008)\end{array}$ & Intercept & $\begin{array}{c}0.005 \\
(0.007)\end{array}$ & Intercept & $\begin{array}{c}0.001 \\
(0.004)\end{array}$ \\
\hline MktMinusRF & $\begin{array}{c}0.981^{* *} \\
(0.427)\end{array}$ & MktMinusRF & $\begin{array}{c}1.267^{* * *} \\
(0.348)\end{array}$ & MktMinusRF & $\begin{array}{c}1.431^{* * *} \\
(0.187)\end{array}$ \\
\hline SMB & $\begin{array}{c}1.251^{* *} \\
(0.525)\end{array}$ & SMB & $\begin{array}{c}0.790^{* *} \\
(0.269)\end{array}$ & SMB & $\begin{array}{c}0.734^{* * *} \\
(0.097)\end{array}$ \\
\hline HML & $\begin{array}{c}0.020 \\
(0.480)\end{array}$ & HML & $\begin{array}{l}-0.047 \\
(0.342)\end{array}$ & HML & $\begin{array}{c}0.044 \\
(0.226)\end{array}$ \\
\hline Mom & $\begin{array}{r}-0.087 \\
(0.270)\end{array}$ & Mom & $\begin{array}{c}0.121 \\
(0.406)\end{array}$ & Mom & $\begin{array}{c}0.105 \\
(0.163)\end{array}$ \\
\hline Observations & 11 & Observations & 13 & Observations & 20 \\
\hline R-Square & 0.8898 & R-Square & 0.9073 & R-Square & 0.9471 \\
\hline
\end{tabular}

Table 6: We form long-only portfolios based on buy recommendations by Jim Cramer over our sample period of November 16, 2005 and June 23, 2006. We compute equal-weighted daily excess returns from these calendar-time portfolios and compound these daily returns to compute monthly returns. We then regress the monthly returns against the Fama-French three factors and a momentum factor. The portfolio formation strategies vary based on the waiting period (1 day or 0 days) and the holding period (50, 100 and 250 days). 
Table 7: Analysis of Cramer's Stock-Picking Ability, No News

\begin{tabular}{|c|c|c|c|c|c|}
\hline \multicolumn{6}{|c|}{ Panel A: Portfolios Formed 1 Day after Recommendation } \\
\hline \multicolumn{2}{|c|}{ Hold Stocks 50 Days } & \multicolumn{2}{|c|}{ Hold Stocks 100 Days } & \multicolumn{2}{|c|}{ Hold Stocks 250 Days } \\
\hline Intercept & $\begin{array}{c}-0.011^{* * *} \\
(0.003)\end{array}$ & Intercept & $\begin{array}{c}-0.012^{* *} \\
(0.005)\end{array}$ & Intercept & $\begin{array}{l}-0.003 \\
(0.004)\end{array}$ \\
\hline MktMinusRF & $\begin{array}{c}0.941^{* * *} \\
(0.184)\end{array}$ & MktMinusRF & $\begin{array}{c}0.943^{* *} \\
(0.318)\end{array}$ & MktMinusRF & $\begin{array}{c}1.124^{* * *} \\
(0.142)\end{array}$ \\
\hline SMB & $\begin{array}{c}1.164^{* * *} \\
(0.137)\end{array}$ & $\mathrm{SMB}$ & $\begin{array}{c}0.937^{* * *} \\
(0.171)\end{array}$ & $\mathrm{SMB}$ & $\begin{array}{c}0.676^{* * *} \\
(0.141)\end{array}$ \\
\hline HML & $\begin{array}{l}-0.041 \\
(0.158)\end{array}$ & HML & $\begin{array}{c}0.070 \\
(0.311)\end{array}$ & HML & $\begin{array}{l}-0.078 \\
(0.195)\end{array}$ \\
\hline Mom & $\begin{array}{c}-0.508^{* * *} \\
(0.112)\end{array}$ & Mom & $\begin{array}{l}-0.152 \\
(0.284)\end{array}$ & Mom & $\begin{array}{c}0.115 \\
(0.199)\end{array}$ \\
\hline Observations & 11 & Observations & 13 & Observations & 20 \\
\hline R-Square & 0.985 & R-Square & 0.884 & R-Square & 0.8994 \\
\hline
\end{tabular}

Panel B: Portfolios Formed on Day of Recommendation

\begin{tabular}{|c|c|c|c|c|c|}
\hline \multicolumn{2}{|c|}{ Hold Stocks 50 Days } & \multicolumn{2}{|c|}{ Hold Stocks 100 Days } & \multicolumn{2}{|c|}{ Hold Stocks 250 Days } \\
\hline Intercept & $\begin{array}{c}0.009 \\
(0.009)\end{array}$ & Intercept & $\begin{array}{c}0.007 \\
(0.012)\end{array}$ & Intercept & $\begin{array}{c}0.006 \\
(0.005)\end{array}$ \\
\hline MktMinusRF & $\begin{array}{c}1.529^{* *} \\
(0.588)\end{array}$ & MktMinusRF & $\begin{array}{l}1.277^{*} \\
(0.637)\end{array}$ & MktMinusRF & $\begin{array}{c}1.344^{* * *} \\
(0.216)\end{array}$ \\
\hline SMB & $\begin{array}{c}0.903 \\
(0.538)\end{array}$ & SMB & $\begin{array}{c}0.536 \\
(0.647)\end{array}$ & SMB & $\begin{array}{c}0.811^{* * *} \\
(0.199)\end{array}$ \\
\hline HML & $\begin{array}{l}-0.553 \\
(0.484)\end{array}$ & HML & $\begin{array}{l}-0.712 \\
(0.709)\end{array}$ & HML & $\begin{array}{l}-0.382 \\
(0.356)\end{array}$ \\
\hline Mom & $\begin{array}{r}-0.034 \\
(0.516)\end{array}$ & Mom & $\begin{array}{c}0.535 \\
(0.650)\end{array}$ & Mom & $\begin{array}{c}0.287 \\
(0.229)\end{array}$ \\
\hline Observations & 11 & Observations & 13 & Observations & 20 \\
\hline R-Square & 0.9084 & R-Square & 0.805 & R-Square & 0.8815 \\
\hline
\end{tabular}

Table 7: As in Table 6, we form long-only portfolios based on buy recommendations by Jim Cramer over our sample period of November 16, 2005 and June 23, 2006. In this table we restrict our sample to stocks that did not have Factiva news announcements in the three day window surrounding the recommendation date. 


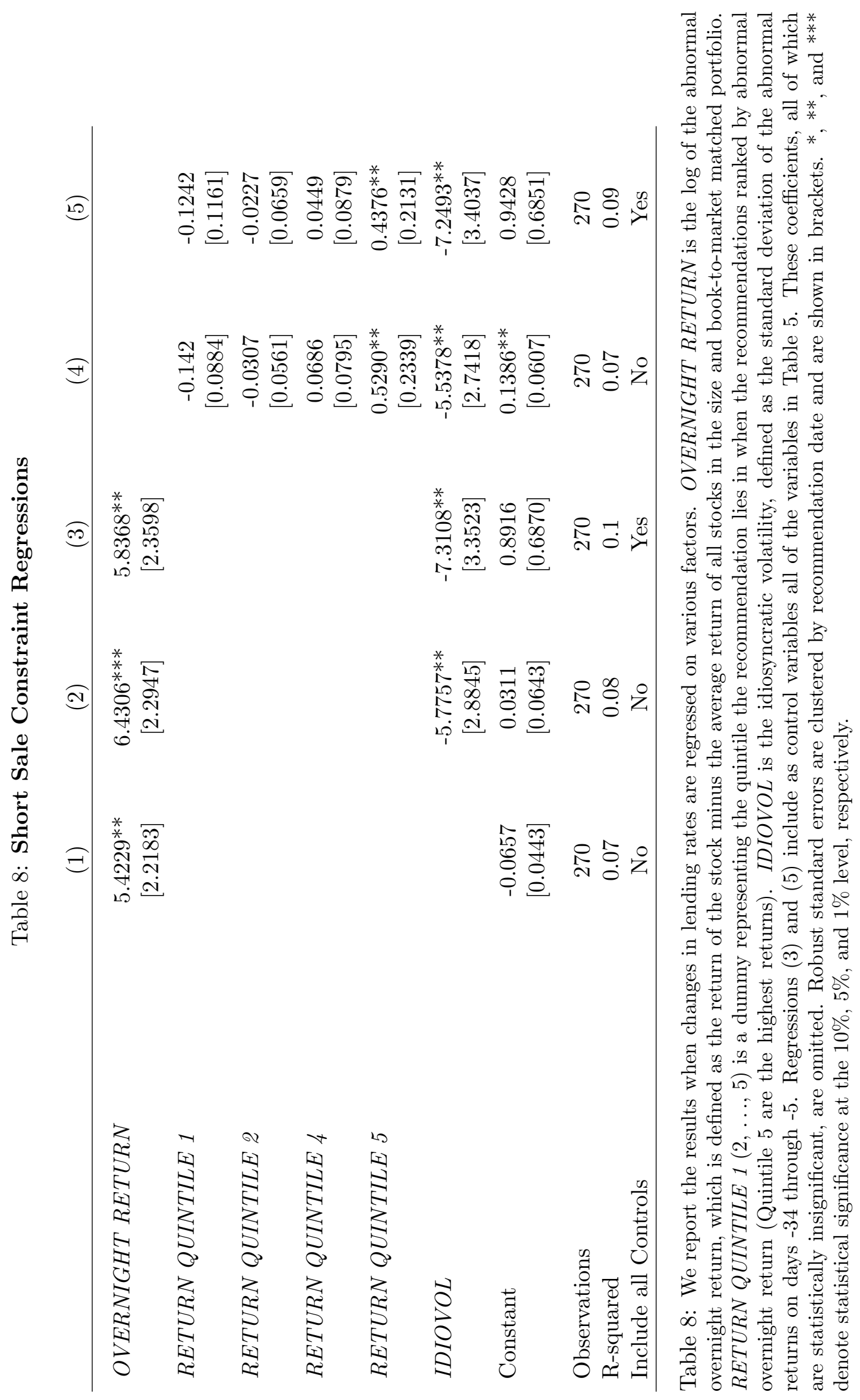




\section{FIGURE 1. Market Response in the Hours Surrounding Cramer's Recommendation}

We plot intraday returns on the day of Cramer's recommendation. Prices are based on recorded trades in the NASDAQ'a historical ITCH data feed, which includes after hours trades on INET. Our sample consists of the 382 stocks with at least one trade on the ITCH data prior to 6 PM on the day of the recommendation. We do not discard ADRs in the top figure because here we do not need to match the stocks to book to market portfolios. The $95 \%$ confidence interval is based on bootstrap sampling. The bottom figure divides the stocks based on their NYSE size quintiles, and ADRs are excluded in these samples.

\section{FULL SAMPLE}

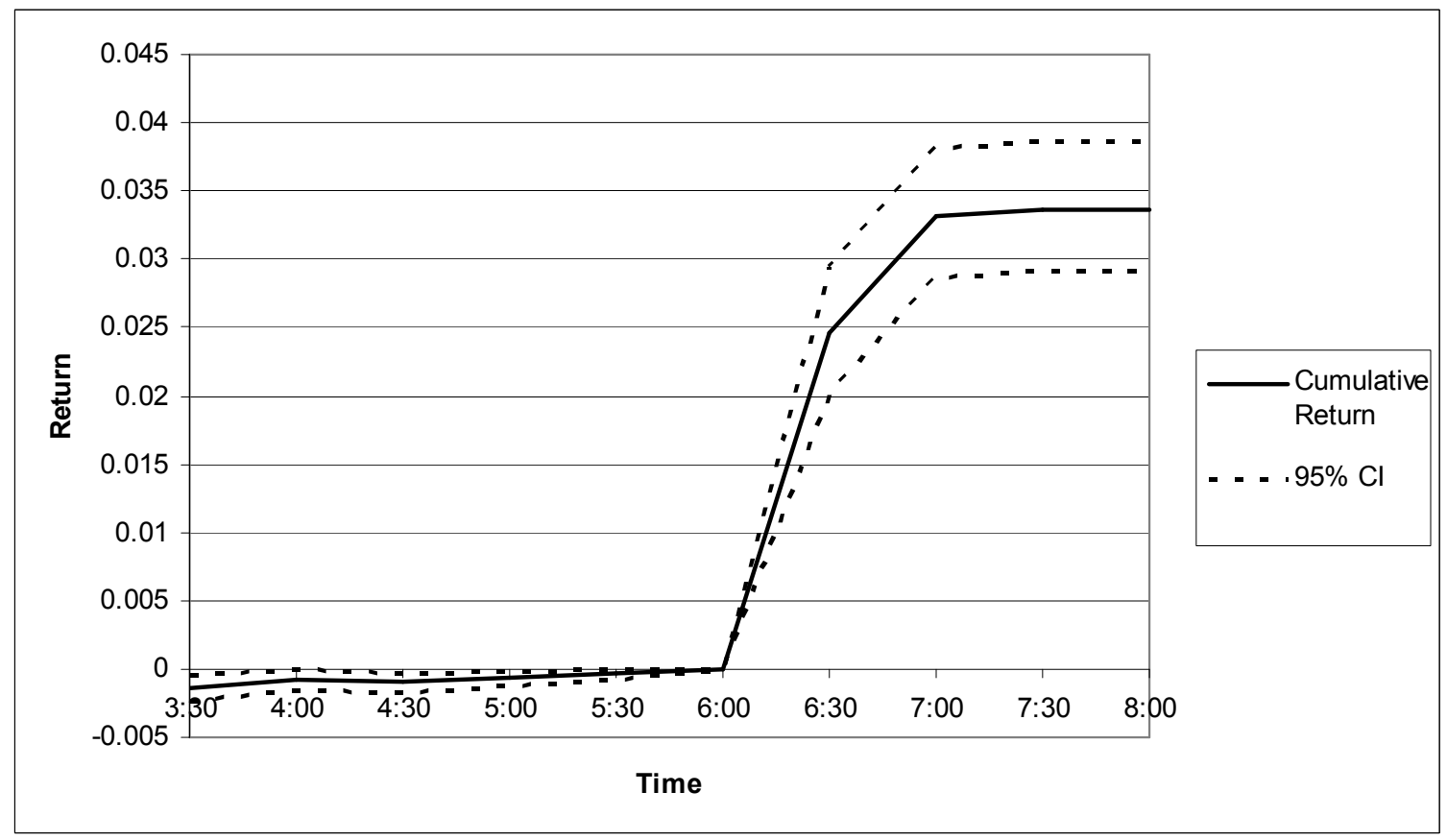

HIGHEST, MIDDLE AND LOWEST QUINTILE

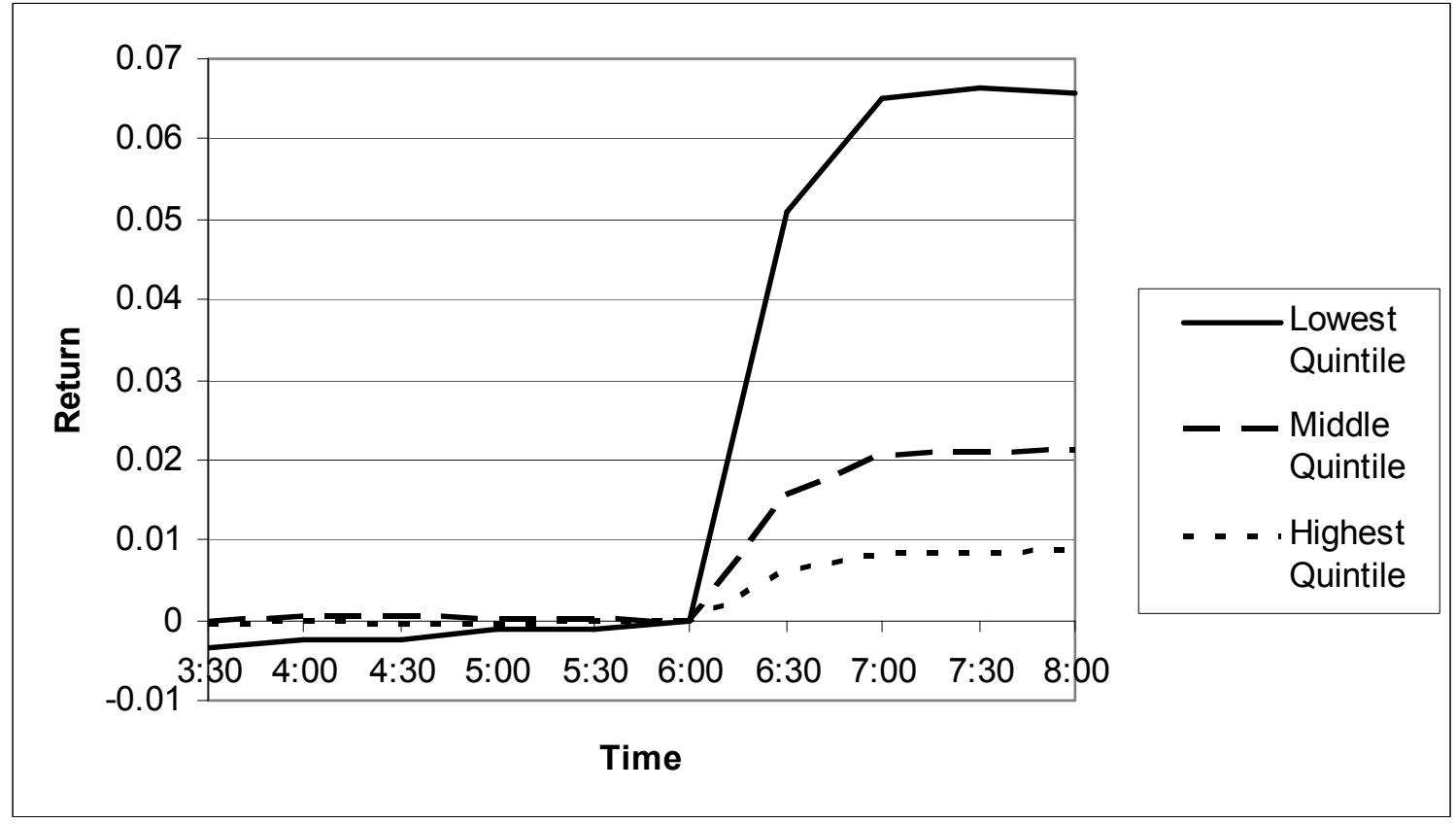




\section{FIGURE 2. Intraday Returns sorted on News/No News and Discussion/Lightning Round}

In the top figure we plot intraday returns based on whether the stock had a news announcements in Factiva during the 3-day window surrounding Cramer's recommendation. The News sample consists of 187 stocks, and the No News sample consists of 195 stocks. (ADRs are included.) In the bottom figure the stocks are divided into the lightning round sample (123 picks) and the non-lightning round sample (259 picks).

\section{NEWS/NO NEWS}

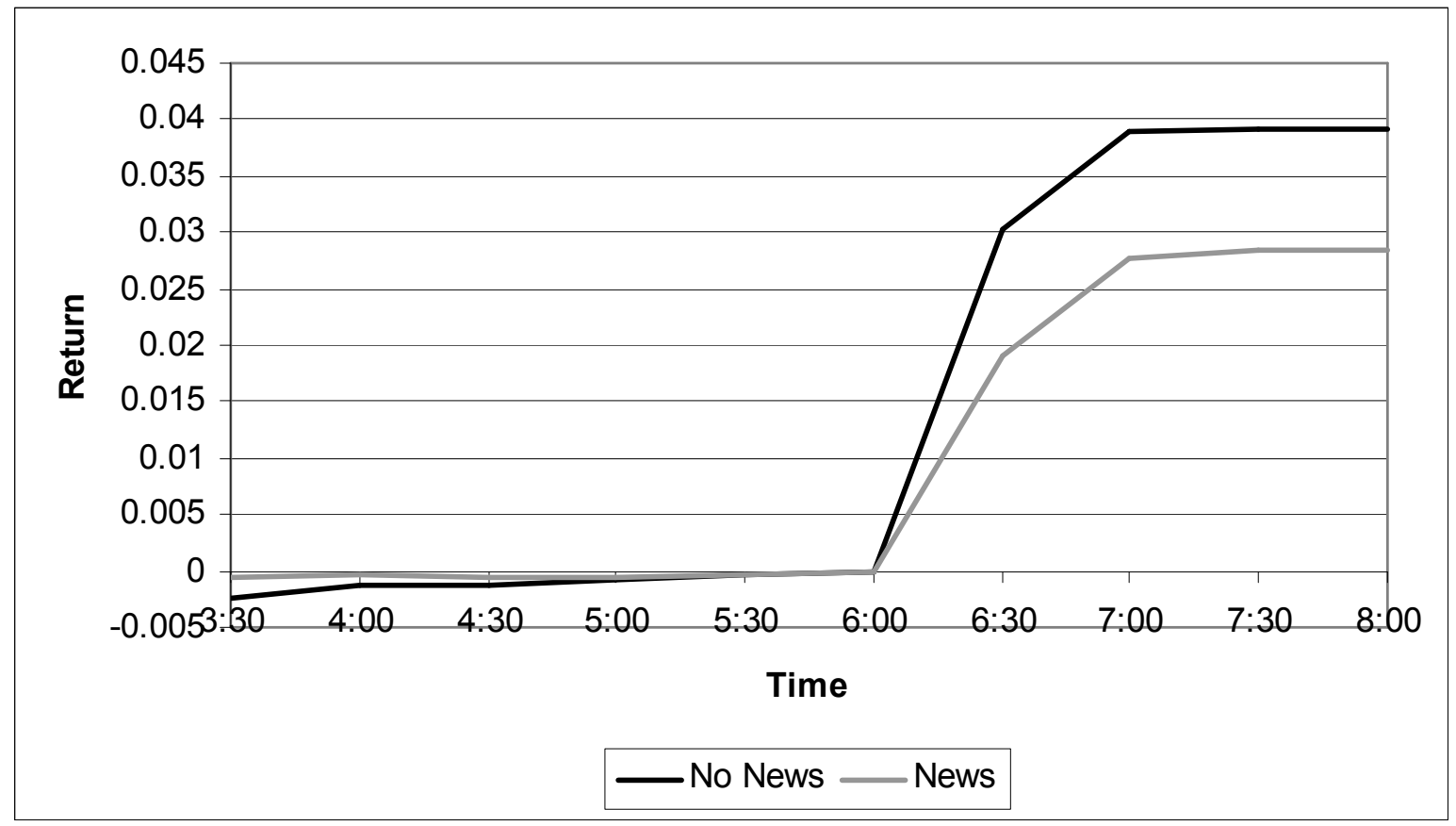

\section{DISCUSSION/LIGHTNING ROUND}

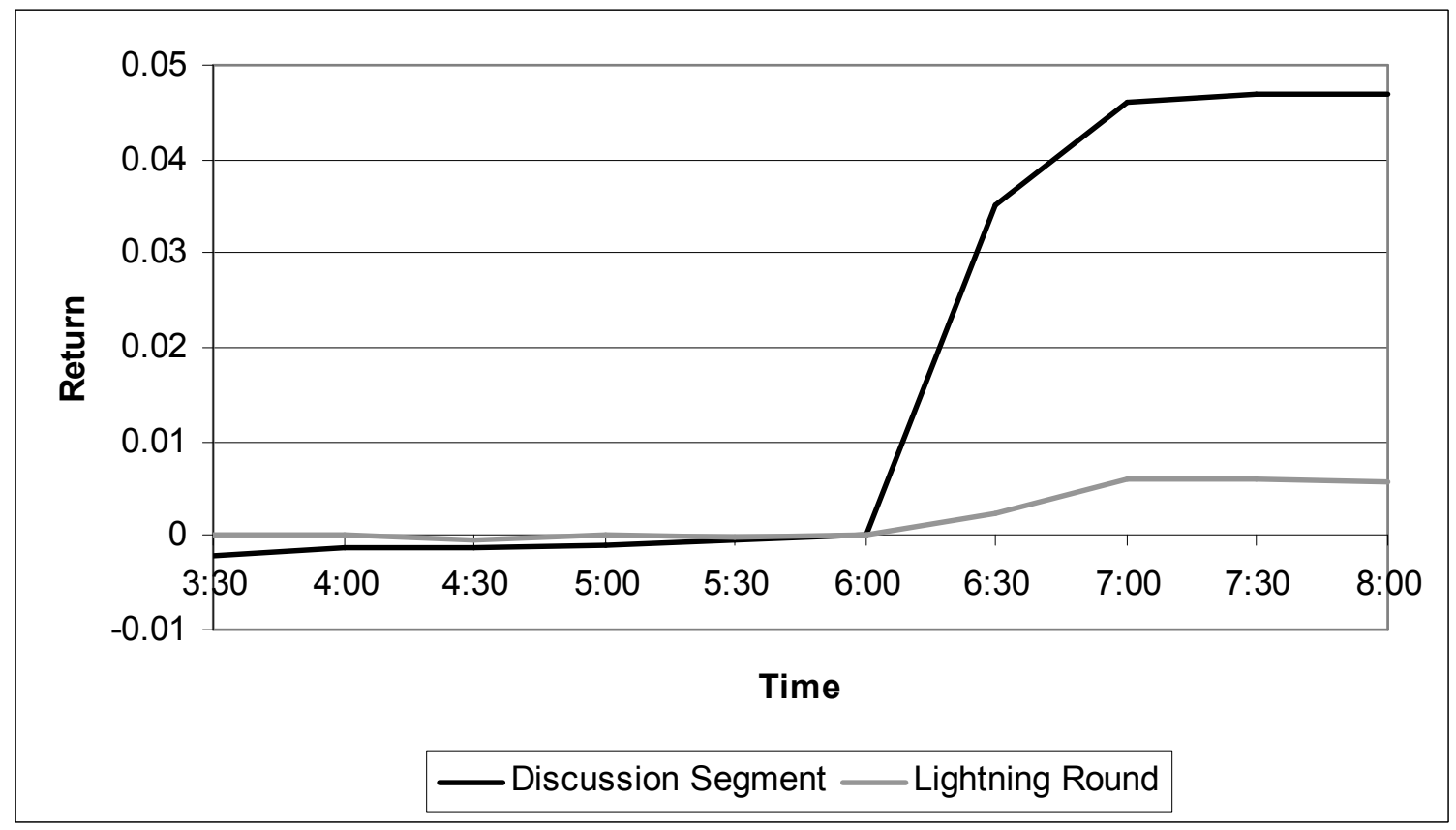




\section{FIGURE 3. Intraday Turnover}

We plot intraday turnover (scaled by 1,000) per thirty minute interval based on trading data from NASDAQ's historical ITCH data feed, which includes after hours trading on INET. Our sample consists of the 351 non-ADRs buy recommendations issued by Cramer. The $95 \%$ bootstrap confidence interval is plotted in dashed lines.

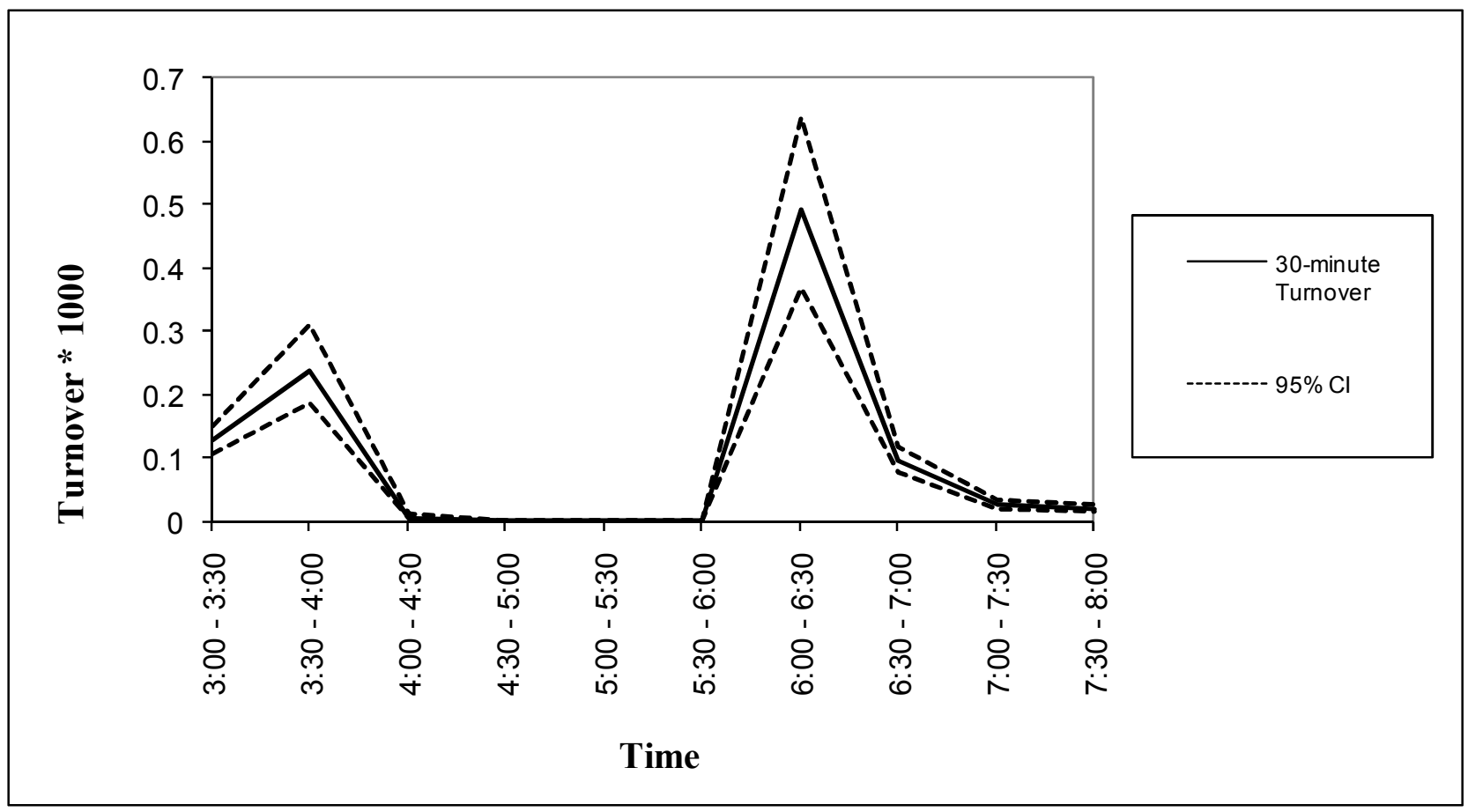




\section{FIGURE 4. Market Response to Recommendations in Event Time}

We plot cumulative abnormal returns (CARs) around Cramer's recommendations in event time, where Day 0 is the day of the recommendation. Abnormal return on a given day is computed as the stock's return minus its matched portfolio's equal weighted return. The top figure is based on the entire sample consisting of the 333 buy recommendations of non-ADRs that can be matched to size and book to market portfolios. The bottom figure is based on the 109 recommendations that lie in the smallest quintile based on NYSE cutoffs. $95 \%$ bootstrap confidence intervals are plotted with dotted lines.

\section{FULL SAMPLE}

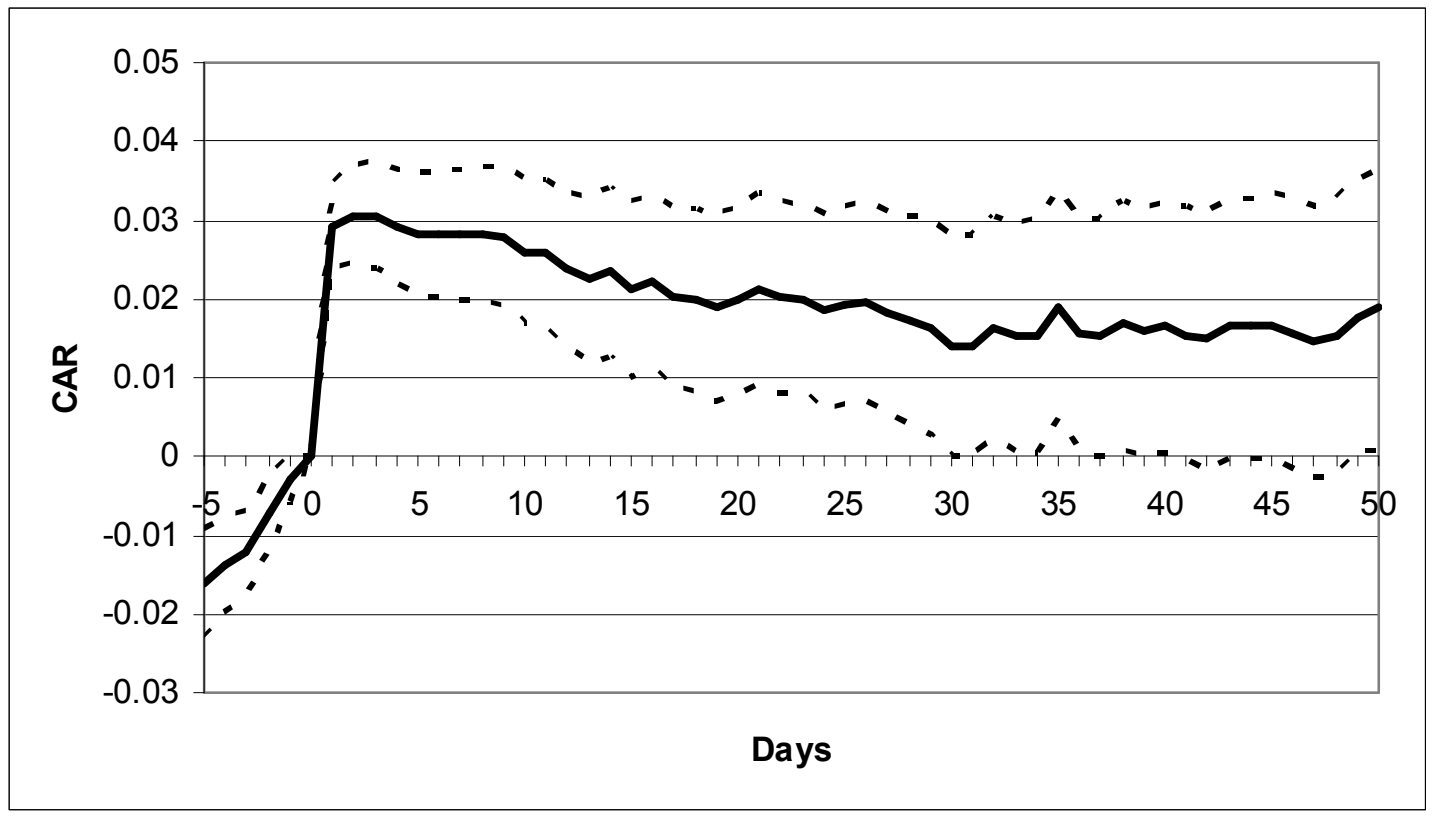

SMALLEST QUINTILE

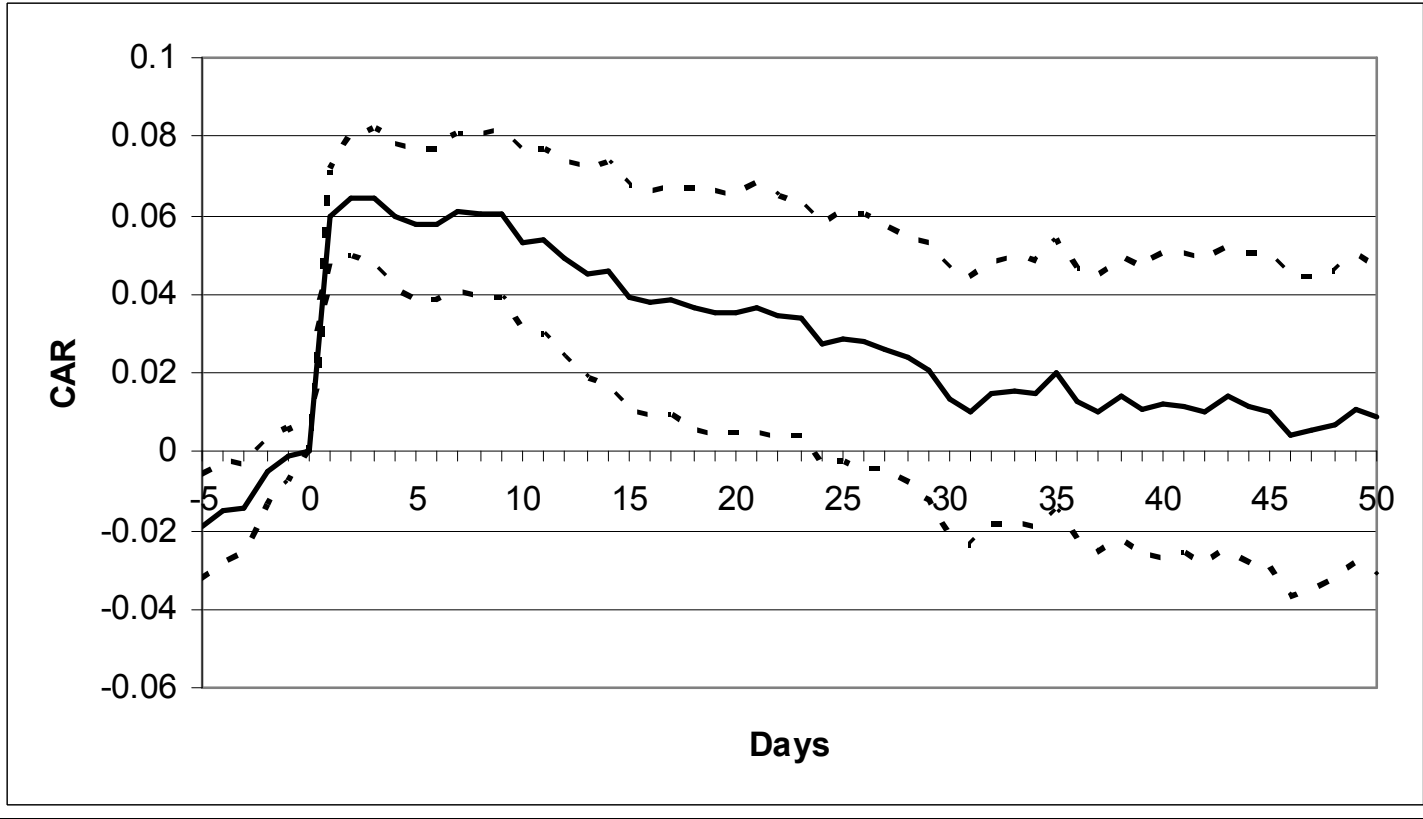




\section{FIGURE 5. Market Response of Stocks with Others News and No Other News}

We plot CARs where the sample is divided based on whether the firm had a (non-Cramer related) news event or not. The "No News" sample consists of 173 firms that had no news announcements in Factiva during the 3-day window surrounding Cramer's recommendation. The "News" sample consists of 160 firms that had a news announcements in Factiva during the 3-day window surrounding Cramer's recommendation.

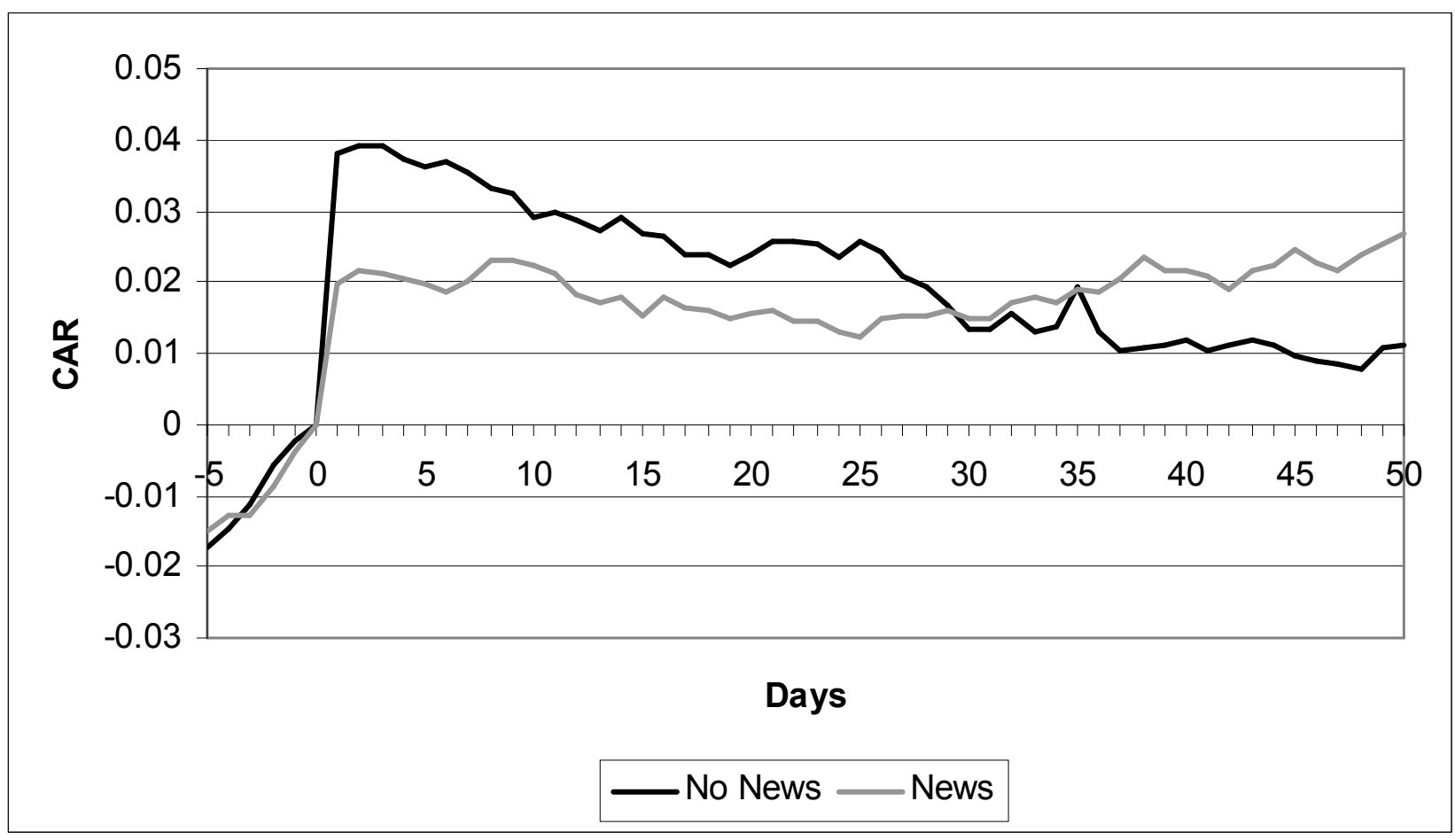




\section{FIGURE 6. Turnover in Event Time}

We plot the stocks' turnover, defined as trading volume divided by shares outstanding. We scale turnover by 1,000 . The top figure consists of 351 non-ADRs that can be matched to CRSP. The $95 \%$ bootstrap confidence interval is plotted in dotted lines. The bottom figure divides the stocks into size quintiles based on NYSE cutoff values.

\section{FULL SAMPLE}

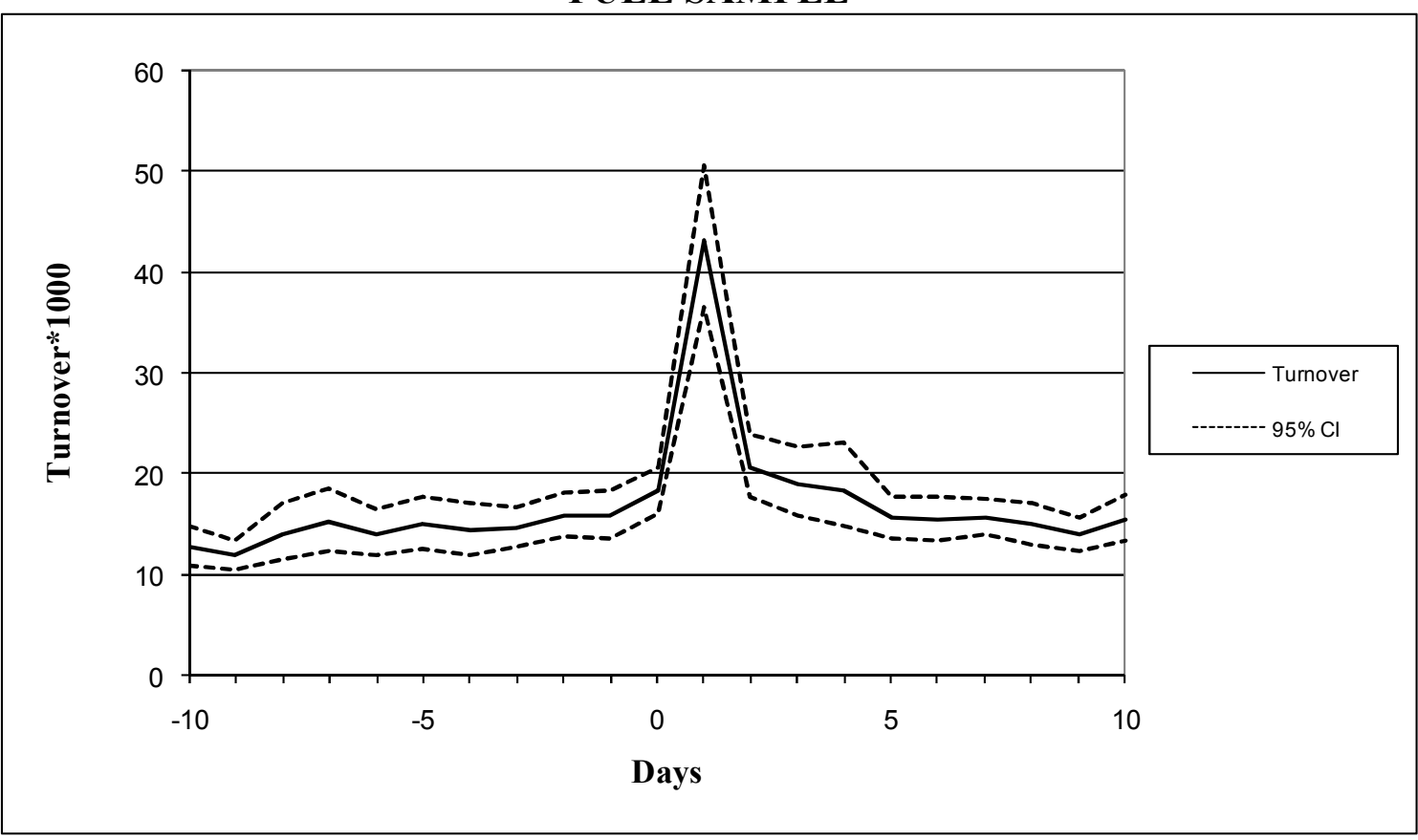

HIGHEST, MIDDLE AND LOWEST QUINTILE

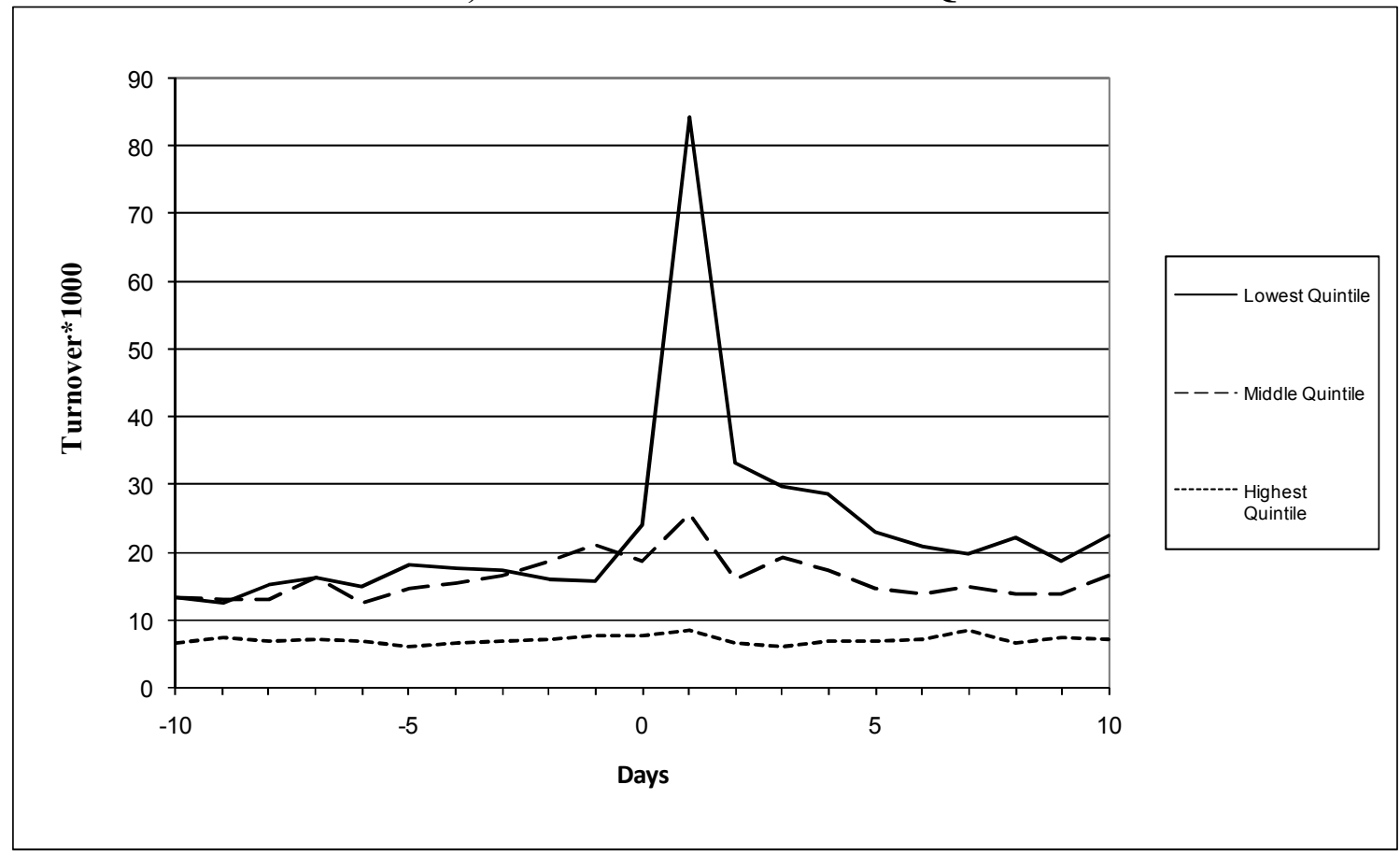




\section{FIGURE 7. Short Turnover in Event Time}

We plot short turnover, defined as short sales volume divided by shares outstanding, in event time. The short volume is taken from NYSE's Reg SHO database. Our measure of short turnover is scaled by 1,000 in the plots. The top sample consists of the 175 non-ADRs recommended by Cramer that appear in the Reg SHO database, and the 95\% bootstrap confidence interval is plotted in dotted lines. The bottom sample is divided based on whether the stocks had a news announcements in Factiva during the 3 day window surrounding the recommendation. The "News" sample consists of 97 stocks, and the "No News" sample consists of 78 stocks.

\section{FULL SAMPLE}

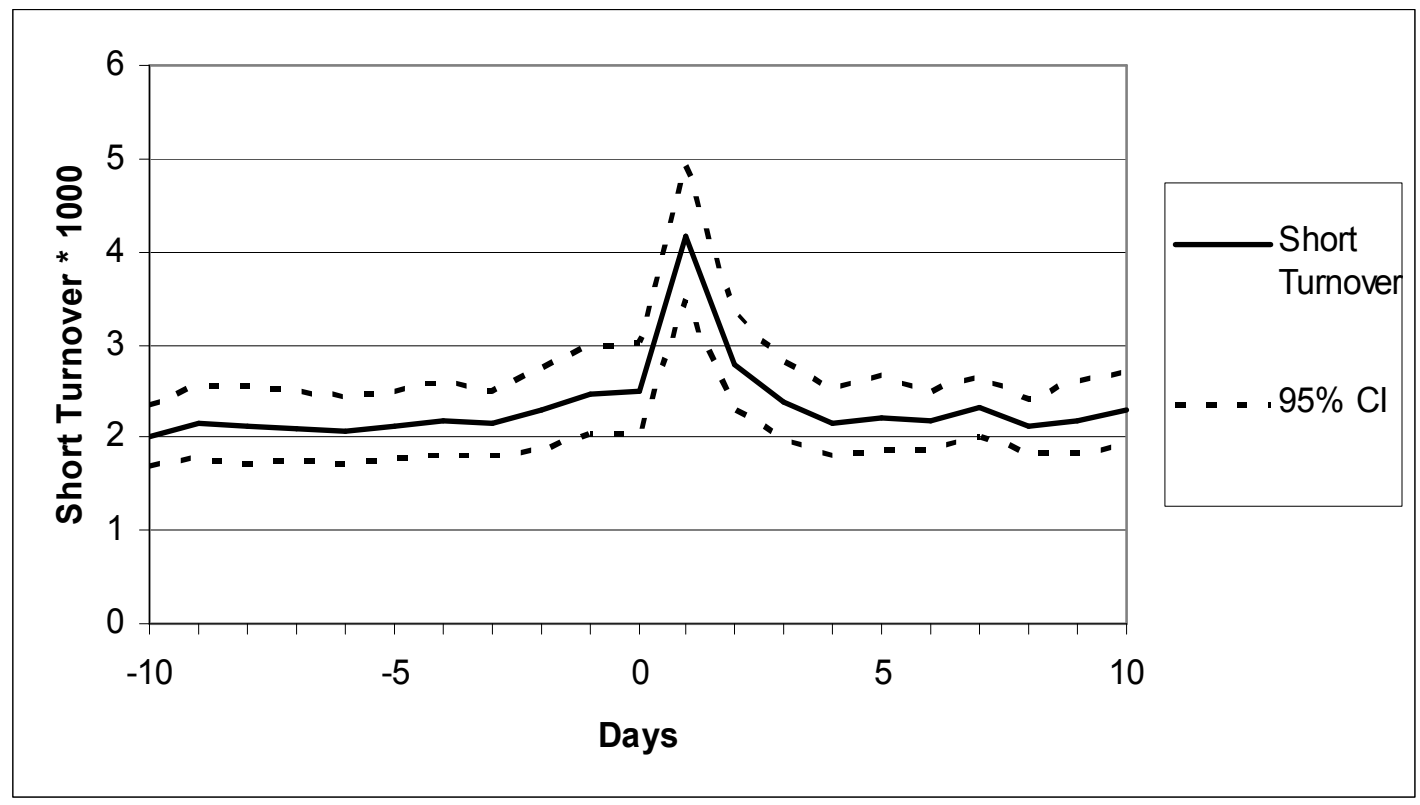

NEWS AND NO NEWS

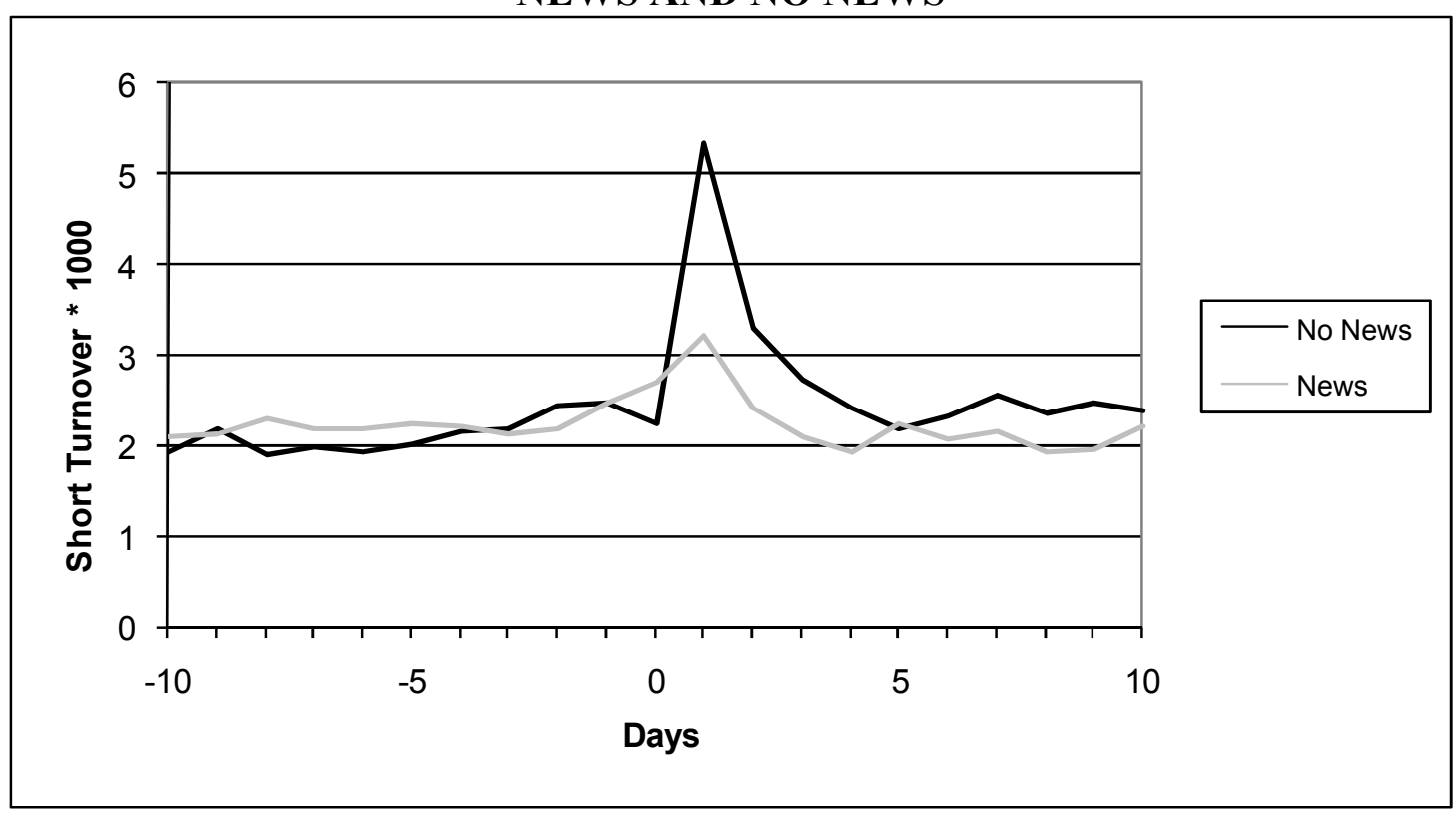

